OPEN ACCESS

Edited by:

Valérie Dutoit,

Université de Genève, Switzerland

Reviewed by:

Mirco Friedrich,

German Cancer Research Center

(DKFZ), Germany

Gregor Hutter,

University Hospital of Basel,

Switzerland

${ }^{*}$ Correspondence:

Maria G. Castro

mariacas@med.umich.edu

Specialty section:

This article was submitted to

Cancer Immunity

and Immunotherapy,

a section of the journal

Frontiers in Oncology

Received: 19 November 2020

Accepted: 06 May 2021

Published: 08 June 2021

Citation:

Garcia-Fabiani MB, Haase S,

Comba A, Carney S, McClellan B,

Banerjee K, Alghamri MS, Syed F,

Kadiyala P, Nunez FJ, Candolfi M,

Asad A, Gonzalez N, Aikins ME,

Schwendeman A, Moon JJ,

Lowenstein PR and Castro MG (2021)

Genetic Alterations in Gliomas

Remodel the Tumor Immune

Microenvironment and Impact

Immune-Mediated Therapies.

Front. Oncol. 11:631037.

doi: 10.3389/fonc.2021.631037

\section{Genetic Alterations in Gliomas Remodel the Tumor Immune Microenvironment and Impact Immune-Mediated Therapies}

\author{
Maria B. Garcia-Fabiani ${ }^{1,2}$, Santiago Haase ${ }^{1,2}$, Andrea Comba ${ }^{1,2}$, Stephen Carney ${ }^{1,2}$, \\ Brandon McClellan ${ }^{1,3}$, Kaushik Banerjee ${ }^{1,2}$, Mahmoud S. Alghamri ${ }^{1,2}$, Faisal Syed ${ }^{1,2}$, \\ Padma Kadiyala ${ }^{1,2}$, Felipe J. Nunez ${ }^{4}$, Marianela Candolfi ${ }^{5}$, Antonela Asad ${ }^{5}$, \\ Nazareno Gonzalez ${ }^{5}$, Marisa E. Aikins ${ }^{6,7}$, Anna Schwendeman ${ }^{6,7}$, James J. Moon ${ }^{6,7,8}$, \\ Pedro R. Lowenstein ${ }^{1,2}$ and Maria G. Castro ${ }^{1,2 *}$ \\ ${ }^{1}$ Department of Neurosurgery, University of Michigan Medical School, Ann Arbor, MI, United States, 2 Department of Cell \\ and Developmental Biology, University of Michigan Medical School, Ann Arbor, MI, United States, ${ }^{3}$ Immunology graduate \\ program, University of Michigan Medical School, Ann Arbor, MI, United States, ${ }^{4}$ Leloir Institute Foundation, Buenos Aires, Argentina, \\ 5 Instituto de Investigaciones Biomédicas (INBIOMED, UBA-CONICET), Facultad de Medicina, Universidad de Buenos Aires, \\ Buenos Aires, Argentina, ${ }^{6}$ Department of Pharmaceutical Sciences, University of Michigan, Ann Arbor, MI, United States, \\ ${ }^{7}$ Biointerfaces Institute, University of Michigan, Ann Arbor, MI, United States, ${ }^{8}$ Department of Biomedical Engineering, University \\ of Michigan, Ann Arbor, MI, United States
}

High grade gliomas are malignant brain tumors that arise in the central nervous system, in patients of all ages. Currently, the standard of care, entailing surgery and chemo radiation, exhibits a survival rate of 14-17 months. Thus, there is an urgent need to develop new therapeutic strategies for these malignant brain tumors. Currently, immunotherapies represent an appealing approach to treat malignant gliomas, as the pre-clinical data has been encouraging. However, the translation of the discoveries from the bench to the bedside has not been as successful as with other types of cancer, and no long-lasting clinical benefits have been observed for glioma patients treated with immune-mediated therapies so far. This review aims to discuss our current knowledge about gliomas, their molecular particularities and the impact on the tumor immune microenvironment. Also, we discuss several murine models used to study these therapies pre-clinically and how the model selection can impact the outcomes of the approaches to be tested. Finally, we present different immunotherapy strategies being employed in clinical trials for glioma and the newest developments intended to harness the immune system against these incurable brain tumors.

Keywords: glioma, immune microenviroment, immunotherapy, mouse model, clinical trial

\footnotetext{
Abbreviations: CNS, Central nervous system; GBM, Glioblastoma; HGG, High grade glioma; ICI, Immune checkpoint inhibitors; LGG, Low grade glioma; MDSC Myeloid-derived suppre,ssor cells; MS, Median survival; OS, Overall Survival; OVs. Oncolytic Viruses; PFS, Progression Free Survival; PBMCs, peripheral blood mononuclear cells; SOC, Standard of care; TAA, Tumor-associated antigen; TILs, Tumor-infiltrating lymphocytes; TME, Tumor microenvironment; TMZ, Temozolomide; Tregs, Regulatory T cells; TSA, Tumor-specific antigen.
} 


\section{INTRODUCTION}

Malignant tumors of the central nervous system (CNS) have an annual rate mortality of 9.01 per 100,000 adults in the US (1). Gliomas are brain tumors which clinically can present as grades II-IV in relation to their malignancy. Glioblastoma, the most aggressive type of glioma (high-grade glioma, WHO grade IV), accounts for the majority of gliomas and the highest incidence rate for malignant tumors of the CNS in adults (3.21 per 100,000 population) (1). This type of aggressive tumor has been subjected to extensive research due to the dismal outcomes of the current standard of care (SOC) therapies (maximal safe surgery, followed by radiation and chemotherapy with Temozolomide), and the lack of improvement in the median survival post-diagnosis (1417 months) (2).

There are several aspects of this type of tumor that makes it difficult to treat (3), such as its anatomical location and the presence of a blood-brain barrier, which hampers the delivery of therapeutics (4); its intrinsic infiltrative nature, that makes it a tumor virtually impossible to resect completely $(3,5)$; and the presence of an immunosuppressive micro-environment, that impedes the natural development of an anti-tumor immune response (6-11). In spite of these challenges, in the last decade, there has been an expansion in the therapies aimed to harness the immune system to direct it against malignant glioma (12). So far, pre-clinical data has demonstrated the effectiveness of immunestimulatory or anti-immunosuppressive strategies, and many clinical trials are currently ongoing to test their efficacy in the clinical arena (12).

This review aims to discuss several aspects related to the glioma immune-microenvironment and the newest strategies that could emerge as a result of the latest pre-clinical investigations. Firstly, we will present the available clinical data regarding the immune microenvironment in glioma and its particularities in terms of tumor classification and molecular features $(7,13-15)$, as well as the current immune-mediated strategies being tested in the pre-clinical field (16). Also, we will overview the present immune-stimulatory therapeutic modalities being tested in clinical trials $(8,17)$. Finally, we will discuss the latest pre-clinical developments related to anti-glioma therapies that could enhance the immune system to develop long-lasting anti-tumor immunity (18-24).

We believe that this review will bring to light the latest improvements in the strategies being developed to treat highgrade gliomas aimed to stimulate an anti-tumor immune response, broadening the spectrum of possibilities to be tested in the clinical setting and bringing new concepts for fighting this devastating tumor.

\section{GLIOMA CLASSIFICATION}

\section{Adult Gliomas}

Glioma involves a heterogeneous group of primary brain tumors originated from neural precursor cells (25), and represent thirty percent of the CNS tumors $(1,26)$. They can be divided in diffuse gliomas and non-diffuse gliomas, which refer to tumors with a circumscribed growth pattern, including ependymomas and other astrocytic tumors $(27,28)$. The majority of adult gliomas are diffuse, distinguished by an infiltrative pattern of growth within the CNS parenchyma, and have been typically classified according to histological features and grade of malignancy (2729). The histological analysis of surgical specimens allows the identification different glioma subtypes: oligodendroglioma, characterized by uniformly rounded nuclei; astrocytoma, with nuclear irregularities and hyperchromasia; and oligoastrocytoma, which is a rare mixed glioma (30). Additionally, based on the grade of anaplasia it is possible to further divide gliomas into four World Health Organization (WHO) subtypes, ranging from WHO grade I to WHO grade IV. WHO grade I gliomas correspond to tumors with slow development and better prognosis; WHO grade II gliomas are defined as low grade gliomas; WHO grade III gliomas are used to describe anaplastic gliomas; and WHO grade IV encompass glioblastoma $(27,28,31)$. Usually, high grade gliomas (HGG) include WHO III and IV gliomas.

The revised 2016 WHO CNS classification includes, for the first time, distinctive genetic/epigenetic alterations to define several groups of gliomas $(28,32)$. The presence and distribution of genetic alterations in brain tumors, such as alterations in PI3K, PDGFR, PTEN, TP53, IDH, EGFR, H3F3A, $A T R X$ and TERT (33-35), are now a criteria used to differentiate glioma subtypes $(28,36,37)$. Each molecular glioma subtype is related to a histologic tumor-class and a particular WHO grade of malignancy $(33,34,38-40)$. The hallmark genetic alteration in adult diffuse gliomas, that promoted the incorporation of molecular features in their classification, is the mutation in isocitrate dehydrogenase 1 (IDH1). This alteration, usually at arginine 132 (IDH1-R132H), is highly frequent in diffuse lowgrade gliomas (LGGs; WHO grade II), in anaplastic astrocytomas (WHO grade III), and also in a smaller proportion of HGG originated from LGGs (secondary glioblastomas; WHO grade IV) $(28,40-42)$. IDH1-R132H (mIDH1) catalyzes the production of 2-hrydroxyglutarate, eliciting epigenetic reprogramming of gene expression (33, 40, $43,44)$ and is associated with better prognosis in glioma patients $(33,39,40,45)$. In addition, the loss of $1 \mathrm{p} / 19 \mathrm{q}$ chromosomal segments define mIDH1-1p/19q-codel and mIDH1-noncodel glioma subtypes. Mutant IDH1-noncodel typically co-occurs with loss-of-function mutations in ATRX and TP53 genes, which are associated with astrocytoma and oligoastrocytoma subtypes (28). Mutant IDH1 1p/19q-codel gliomas are usually oligodendrogliomas and frequently co-express mutations in TERT promoter (TERTp) and CIC (28, 39-41). In adults, diffuse wild type (wt) IDH1 gliomas appear principally in patients over 50 years old and commonly are HGG, WHO grade IV of malignancy $(28,31,39)$. These HGG generally harbor mutations in TP53 and TERTp, with retention of ATRX function. They can also present alterations in the chromosomes 7 and 10, deletions in $C D K N 2 A / B$, and changes in genes involved in the RTK-RAS-PI3K signaling cascade, such as PTEN mutation or loss or EGFR amplification $(28,31,32,34)$. Importantly, the DNA methylation, which typically occurs at 
cytosines followed by a guanine separated by a phosphate group (CpG site), emerges as a distinctive parameter to refine tumor classification with clinical implications, especially in cases with ambiguous histology. The CpG-island methylator phenotype (GCIMP) is closely related with IDH1 mutation and is associated with better prognosis in gliomas $(46,47)$. On the other hand, demethylation in CXCR4, TBX18, SP5, and TMEM22, genes have been linked with initiation and progression of glioblastoma (48). DNA methylation profiling has been shown to be highly robust and reproducible. In diffuse glioma TCGA patients, Ceccarelli et al., identified glioma DNA methylation clusters (LGm1-LGm6) linked to different molecular glioma subtypes (40). More recently, Capper et al, developed a DNA methylationbased classification system, which allowed to define five categories of methylation classes of CNS tumors, which resulted in a change of diagnosis in up to $12 \%$ of prospective cases analyzed (49); and in the positioning of this method as a powerful tool to improve glioma classification. In addition, the analysis of DNA methylation profiles has utility in therapeutic decisions. The presence of methylated $\mathrm{CpG}$ islands in the O6methylguanine-DNA methyltransferase (MGMT) promoter is a molecular marker of better response to DNA alkylating agents (50), indicating that the methylation status of MGMT promoter is a critical feature to design glioma treatment.

In summary, adult gliomas are classified by histological features and by molecular lesions, that define distinctive tumor entities, which are associated with different grades of malignancy. This classification is relevant for diagnosis, prognosis and clinical decisions. In addition, the updated CNS-WHO classification for brain tumors is a valuable source to improve and conduct accurate studies of gliomas, considering the intrinsic biological features of the different glioma subtypes.

Currently, the adult glioma SOC includes maximal safe surgery when is possible; chemotherapy, generally with temozolomide (TMZ); and focal radiation (17, 51). However, in spite of intense investigation for years, no substantial clinical improvements have been observed (51). This unfortunate fact encourages the development novel therapeutic approaches for a wide spectrum of glioma patients who are waiting for an effective treatment.

\section{Pediatric Gliomas}

High grade gliomas comprise $~ 15 \%$ of all central nervous system (CNS) pediatric tumors (52), and have an incidence of approximately 0.85 per 100,000 children (26). Pediatric high grade gliomas ( $\mathrm{pHGG)}$ and diffuse intrinsic pontine gliomas (DIPG) (recently included into the classification of Diffuse midline glioma (DMG)) are highly aggressive gliomas, which, unlike the adult counterparts, occur throughout the CNS anatomy. The prognosis for pHGG is dismal, with an overall median survival of 9-15 months and a 5-year survival rate of less than $20 \%$ (53).

Brainstem gliomas are more prevalent in childhood, whereas hemispheric pHGG, are more prevalent in adolescents (54). Several characteristics distinguish pHGG from adult gliomas, such as molecular (genetic and epigenetic), and clinical features (55).
Particularly, advancements in molecular high-throughput profiling over the last few years improved our understanding of pHGG and led to the identification of unique genetic and epigenetic features of these tumors. Most notably, the discovery of recurrent mutations in the genes encoding histone variants $\mathrm{H} 3.3(\mathrm{H} 3 \mathrm{~F} 3 \mathrm{~A})$ and H3.1 $(H I S T 1 H 3 B / C)$, and other genes associated with epigenetic mechanisms, demonstrated the unique biology of pediatric brain tumors $(53,56,57)$. Three somatic mutations resulting in the replacement of a lysine with a methionine at residue 27 of histones H3.1 and H3.3 (K27M) in brainstem/midline pHGG, or the replacement of a glycine to arginine or valine at residue 34 (G34R/V) of the histone H3.3 in hemispheric pHGG were found to be characteristic of these tumors $(53,57)$. These mutations rewire the epigenome, resulting in global hypomethylation and disrupt critical regulatory sites of post-translational histone modifications (56). These mutations are exclusive, are found at specific anatomical locations, within distinct age groups and patients harboring these tumors have different survival outcomes $(38,56)$.

The WHO classifies pHGGs as anaplastic astrocytoma (WHO grade III) and glioblastoma (GBM; WHO grade IV) (28). Among midline pHGG, the updated 2016 WHO classification of tumors of the CNS classifies the DMG H3-K27M-mutant as an independent entity, WHO grade IV (58). DMG H3 K27M-mutant arises in all midline CNS structures, are astrocytic tumors, and represent the majority of infiltrative brainstem glioma (59).

The histological characteristics of pHGG include hypercellularity, nuclear atypia, abnormally high mitotic activity, and increased angiogenesis and/or necrosis, the latter two associated primarily with GBM morphology (60). Due to their proliferative nature, HGG have shorter duration between symptom onset and diagnosis compared to tumors of lower grade, precluding the clinical advantages of early detection (61, 62). Surgical intervention of non-brainstem pHGG patients includes tumor resection and biopsy, although total tumor resection is often impossible in pHGG, particularly for midline $\mathrm{pHGG}$, as these infiltrative tumors often progress into normal tissue beyond surgical margins (58). However, the extent of resection is one of the few significant prognostic markers for overall survival (OS) in pediatric patients with pHGG (63). Although surgery is the primary intervention for treatment of non-brainstem pHGGs, it is not curative. Standard of care also includes radiation therapy for pHGG patients above three years of age, typically 50-60 Gy delivered over 3-6 weeks (61). Currently, no chemotherapeutic treatments are involved in the SOC for pHGG; however, various are being tested in clinical trials (64). Despite immense efforts, there are no effective treatment options and pHGG has become the leading cause of cancer related death in children and adolescents under the age of 19 years $(26,60)$.

There is a diversity of molecular alterations driving $\mathrm{pHGG}$ and therapies must be accordingly diverse and specific. Highly targetable molecular alterations are found in different subtypes of non-brainstem pHGG. For example, pHGG often carry genetic alterations in the TP53, PTEN/PI3K/Akt, PDGF or Ras pathways, which include targets that can be druggable (65). However, immunotherapies specifically designed for pediatric brain tumors have been understudied. Pre-clinical models for 
pHGG and the testing of immune-mediated therapeutic approaches are starting to emerge $(66,67)$, which open new avenues for the treatment of these aggressive pediatric brain tumors.

\section{GLIOMA IMMUNE MICROENVIRONMENT}

\section{Crosstalk Between the Healthy CNS and the Immune System}

The brain has for long been considered an immune privileged site due to the absence of immune response after the heterotopic transplantation of skin xenografts (68). However, in the same set of experiments, Medawar et al. observed that if the immune system had been previously exposed to the tissue graft in any other site of the body and then the transplantation was done in the brain, a powerful immune response invaded the CNS, causing grafting breakdown and rejection (68). These data showed that the CNS in not immune-isolated and that even though an immune response against xenografts cannot be easily started in the brain parenchyma, it can reach this site in a pre-immunized state.

Due to anatomical particularities, the crosstalk between the CNS and the immune system differs from the immune response mounted in any other organ of the body (69-72). For instance, the passage of molecules and cells, such as immune cells, to the brain parenchyma is subjected to a strict control by the endothelial blood-brain barrier (BBB) (69). Also, the absence of classic lymphatic drainage in the CNS was considered to be the cause of the lack of an afferent arm of the immune system; i.e. the route of antigen transportation from the site of infection/trauma to the nearby lymphatic node (69). However, maintaining the brain as an immune-isolated tissue would be dangerous, thus many efforts had been destined to understand the mechanism by which the immune system surveils the CNS. There are two types of fluids in the CNS: the cerebrospinal fluid (CSF), in the ventricles and the subarachnoid space; and the interstitial fluid in the brain parenchyma. Even though both types of fluids drain to the cervical and lumbar lymphatic nodes, they do it through separate routes: while the CSF drains across the cribriform plate and the dura mater lymphatics, the interstitial fluid drains via perivascular channels into the lymph nodes or the $\operatorname{CSF}(69,71)$. This narrow space does not allow the passage of cells, but it permits antigen transportation to the nearest lymph node, where adaptive immune response could be started. In contrast, the drainage pathways of the CSF allow cell trafficking and this fluid has a more active crosstalk with the immune system $(69,73)$. In fact, healthy individuals contain up to 700,000 cells in total in the CSF (70). Around $80-90 \%$ of these cells are T cells, majority of which are memory T cells $(70,73)$. Also, a small proportion DCs has been found in the CNS, and there is evidence that DC can scan the CSF for foreign antigens and reach the lymphoid organs to activate $\mathrm{T}$ cells in the periphery $(70,72)$.

Even though these data demonstrate the interconnection between the immune system and the healthy CNS, this site usually remains quiescent and immunosuppressed due to the presence of factors derived from neural cells $(70,73)$. For instance, the brain parenchyma contains only one type of immune cell: the microglia. These cells are tissue resident macrophages, but they originate from a different embryonic layer than circulating macrophages $(73,74)$. These cells are kept in an inactivated state through the interaction of the CD200 receptor in neural cells and CD200 ligand in microglia (75). Even though these cells are capable of antigen presentation, the levels of MHC in microglia and other astrocytes remains low (73). However, in response to an infection, microglial cells become activated and produce an array of pro-inflammatory mediators, to facilitate the recruitment and activation of innate and adaptive immune cells (76). After an inflammatory stimulus, the immune privilege of the brain switches, increasing the permeability of the BBB and the infiltration of myeloid cells and activated $\mathrm{T}$ cells, as well as the proliferation of microglial cells $(73,76-78)$. This state causes phenotypic changes as well, such as CD11c, MHCII and costimulatory molecules' upregulation $(73,78)$.

\section{Immune Microenvironment in Brain Tumors: General Concepts}

The shift in the dogma of the CNS as an immune inert site, prompted the development of immunotherapies against glioma. Glioblastoma is one of the deadliest type of tumor and currently patients succumb to this disease even after their treatment with SOC (79). Thus, researchers have been devoted to find therapeutic alternatives to harness the immune system and direct it against this tumor. Today, there are several ongoing clinical trials testing different type of immunotherapies, but the results obtained so far have not been as encouraging as the effects observed in pre-clinical models and the great majority have not been tested in Phase III yet $(12,79)$.

There are several aspects related to the biology of gliomas that make them difficult to treat by immunotherapies. For instance, these tumors tend to have high intra-tumoral heterogeneity, so that finding a tumor specific antigen as a target for immune mediated therapies is difficult and usually approaches involving tumor antigens require the inclusion of more than one target to prevent antigen scape (80-82). Also, the intact BBB prevents the readily penetration of chemotherapeutics to the brain parenchyma, though its permeability can be affected in an inflammatory state (83). Finally, the immune microenvironment of these tumors tends to be immunosuppressive, hijacking the efficacy of immune mediated strategies $(6,8,9,12,78)$.

Glioma tumor immune microenvironment (TME), refers to all those immune cells infiltrating the tumor mass. Even though the diversity of cell infiltration can vary depending on the type of brain tumor (revised below), glioma TME has usually been found to be immunosuppressive $(6,7,11,84)$. Animal models as well as the analysis of human samples have shed light on the characteristics of glioma TME. Myeloid cells are the major type of immune cell in glioma's TME, with macrophages representing more than $30 \%$ of the tumor mass $(6,85)$. This group encompasses bone-marrow derived macrophages and tissue-resident derived macrophages $(13,74)$. It is not clear if these two populations have different functions in glioma or if they are associated with tumor progression, but they have been 
encountered at different locations: while microglial cells were found at the tumor border, bone-marrow derived macrophages were detected at the tumor core (86). These two types of cells are generally known as tumor-associated macrophages (TAMs). Also, infiltrating monocyte-derived macrophages constitute $85 \%$ of the total macrophage population in glioma and it has been observed that prevention of monocyte infiltration extended de median survival of tumor-bearing animals (86). There have been detected expression markers and differential transcriptional landscapes that can be used to distinguish these two populations (86-88). For instance, resident microglia express P2Y12, TMEM19, and are CD45 low, whereas macrophages express CD44, CD169 and are CD45 high (87). More importantly, these two cells' subclasses have been identified in human samples, in which intratumoral blood-derived macrophages displayed a more immunosuppressive transcriptional program and their presence correlated with tumor malignancy (86).

Myeloid-derived suppressor cells (MDSC) are a type of immature myeloid cells that are known to have immunosuppressive functions via different mechanisms that ultimately inhibit T cell functions $(9,11$, 13). These cells have been found in the blood of glioma patients and in the tumor mass, and they have also been characterized in animal models $(9,15,89,90)$. Usually, MDSCs are divided phenotypically in monocytic MDSCs (M-MDSCs) and polymorphonuclear MDSCs (PMN-MDSCs). In humans, M-MDSCs are characterized by CD11b +HLA-DR-CD14+CD15-CD33high, whereas PMN-MDSCs express CD11b+CD66b+CD15+CD14-/dimCD33dimHLA-DR[PMCID: PMC6447515]. In mouse, MDSCs characterization entails less markers: M-MDSC are defined as CD45+/CD11b+Ly6G-Ly6C+ and PMN-MDSCs as Cd45+/CD11b+Ly6G+Ly6C- (91). It has been observed that the quantity and activation status of MDSC inversely correlates with patient survival and that they can be a predictor of WHO tumor grade (90). Moreover, whilst MDSC infiltration after surgery has been associated with poor prognosis, MDSC decrease correlated with better prognosis and an increase in DC infiltration (90).

Lastly, tissue hypoxia, which is common in GBM due to the inefficient neovascularization (10), induces regulatory T cells (Tregs) activation and tumor-promoting phenotype of tumor associated macrophages $(10,92)$. The presence of Tregs can suppress cytotoxic $\mathrm{T}$ cell activities, leading to tumor progression. Moreover, tumor cells as well as immunosuppressive tumor infiltrating immune cells, secrete an array of cytokines that promote and maintain the immunosuppressive microenvironment, not only affecting tumor infiltration, but also cellular differentiation at the bone marrow level $(10,84)$. Some of the cytokines encountered in the TME are IL-10, TGF $\beta$ and IL-6. These are related to NK and T-cell activities inhibition and their expression is related to glioma progression (93).

\section{Immune Infiltration Patterns in Brain Tumors With Different Genetic Landscapes: Lessons From The Clinic and Animal Models}

It is clear that immunosuppression is a common feature of gliomas that enables tumor progression and malignancy. However, the composition of the immune cell infiltrate varies among the type of tumor and certain immune cells are associated with particular genetic alterations usually found in gliomas, such as mutations in IDH1 (94).

The transcriptional landscape of GBM has been classified at least in three different types: proneural, classical and mesenchymal, which correlate with the presence of different genetic alterations $(95,96)$. This classification not only describes inter-tumor differences, but also intra-tumoral variability, as samples taken from distinct regions and at different times thought-out treatment showed diverse transcriptional signatures. With the emergence of Single cell RNA-Seq (scRNA-Seq), the cellular composition of glioblastoma was found to be even more complex. It has been observed that tumor cells can exist in four different phenotypes: mesenchymal-like, astrocyte-like, oligodendrocytic precursor cell-like and neural progenitor cell-like (80). These different cellular states are correlated with different genetic mutations and with the transcriptional signatures defined previously, with neural progenitor cell-like and oligodendrocytic precursor celllike cells associated with the proneural subtype; mesenchymallike cells with mesenchymal subtype; and mesenchymal subtype and astrocyte-like cells associated with classical subtype (80). This complexity in the phenotype of gliomas has been found to have a correlation with the composition of immune cell infiltrate (7).

Tumor microenvironment composition in adult glioma has been lately characterized. Luoto et al. performed a regressionbased gene expression deconvolution to estimate the proportions of particular immune cell types based on RNA-Seq analysis of 156 primary GBM samples generated by The Cancer Genome Atlas (97). They found that cases could be grouped into three immune-response groups which were the following: negative, humoral and cellular-like. They also found that differences in adaptive immune response could be associated with the specific subtypes of HGG defined above. They describe that the "negative" subgroup, which is associated with the negative regulation of lymphocyte response, encompass the proneural subtype, including those samples with CDK4-MARCH9 locus amplification and IDH1 mutation. The mesenchymal subtype was more prevalent in the "humoral" subgroup, in which gene signature was related to B-cell and humoral response components. Finally, the "cellular-like" subgroup was more populated with classical subtype samples, as well as with samples with EGFR amplification. Also, they observed that immune-related responses correlated with the presence of specific genetic alterations. Samples with CDK4 locus amplification or IDH1 mutations were found to be less infiltrated by macrophages, and to have less CD4+ components. On the contrary, samples with NF1 inactivation had a higher macrophage content. This observation has been confirmed in the study of Wang et al. (98). Even though none of the cell components described in the work by Luoto et al. correlated with patient survival, the presence of high activity related to the "antigen presentation and interferon response" cluster was a positive predictor of longer OS. Similarly, Caleb Rutledge $\mathrm{W}$. et al., also found a correlation between tumor- 
infiltrating lymphocytes (TILs) and GBM transcriptional subclasses and they show that TILs were enriched in the mesenchymal class compared with all other classes (99). Also, they did not observe a correlation between IDH1 mutation and TIL presence, nor did they with patient OS (99).

The correlation of IDH1 status and TME composition has been extensively characterized (94). In general, as presented above, IDH1-mutant (mIDH1) gliomas tend to be less populated with TILs when compared to IDH1-wt tumors. Specifically, less CD8+ cytotoxic T cells have been found in mIDH1 gliomas and this could be explained by the reduced expression of chemoattractant cytokines to T cells by mIDH1 glioma cells $(100,101)$. Also, and in correlation to what Luoto et al. found, mIDH1 gliomas tend to have less macrophages than wt-IDH1 tumors (97). Moreover, in an animal model of mIDH1 glioma in the context of ATRX and TP53 mutations, it has been observed that the presence of this mutation reprograms the tumor cell transcriptome, which affects not only immune cell infiltration but also the bone marrow differentiation of the granulocytic lineage (15). This effect was found to be mediated by G-CSF secretion by mIDH1 glioma cells, which prompted the expansion of preneutrophils, while reducing the immunosuppressive phenotype of the granulocytes encountered in mIDH1 tumors' TME (15).

Tumor microenvironment in pediatric gliomas has been less characterized than the adult counterpart, in part because of the small amount of samples available. Thus, it is difficult to correlate molecular subtypes of pediatric tumors with TME infiltration patterns. However, the data gathered so far in the pediatric population show differences in relation to the immune infiltrate characteristics observed in adult patients. In the study of Plant et al., they analyzed 22 pediatric brain tumor tissue samples of mixed diagnoses and they observed no correlation between the amount of $\mathrm{T}$ cells and the aggressiveness of the tumor or the patient survival (102). Griesinger et al., analyzed different types of pediatric brain tumors, which consisted in 7 pilocytic astrocytomas (PA), 19 ependymomas (EPN), 5 GBM, 6 medulloblastomas (MED), and 5 non-tumor brain (NT) control samples. They show PA and EPN to be the most enriched tumors in myeloid cells, with GBM at the third place, but still with more myeloid cells than the NT samples (103). These cells expressed makers for both, immune activation (HLADR and CD64) and immunosuppression (CD206 and CD163). T cell infiltration was also evaluated and GBM had more $\mathrm{T}$ cells than the NT control $(0.79 \%$ vs $0.02 \%)$, exhibiting a 46 -fold and 26-fold increase in CD8 and CD4 T cells, respectively. Also, the average $\mathrm{CD} 8 / \mathrm{CD} 4$ ratio, which was shown to be a prognostic factor in other types of cancer, was elevated in GBM with respect to NT controls: 2.83 vs 0.83 , respectively (103). Moreover, Lieberman et al., studied the TME in DIPG, a pediatric high grade glioma that occurs in the pons. They conclude that the TME of these tumors do not show strong evidence of immunosuppression or inflammation, so that immune-directed therapies against these tumors should focus on immune cell recruitment to the tumor site (104). In this regard, Mendez et al. demonstrated the efficacy of an immunestimulatory gene therapy in increasing the median survival of tumor bearing mice in a pre- clinical mouse model for DIPG harboring mutant ACVR1 gene (66). They show that this therapy was effective in promoting the activation and the infiltration of anti-tumor CD8 T cells (66). Lastly, using a model for pediatric HGG harboring the H3.3G34R mutation it has been demonstrated that these tumor exhibit a more permissive TME with respect to the control group without the mutated histone $(105,106)$. Researchers show that H3.3-G34R tumors are less populated with MDSC and that these cells are not immunosuppressive. Also they observed an increased infiltration of T cells, DCs and M1 macrophages; and an increased sensitivity of glioma cells to IFN $\gamma$-induced apoptosis $(105,106)$.

In conclusion, these data gathered from clinical samples and pre-clinical models highlight the complexity of the immune cell infiltrate in brain tumors and the importance of taking into account the particularities of each type of glioma when considering the application of immune-mediated therapies.

\section{MOUSE MODELS TO STUDY GLIOMA IMMUNE MICROENVIRONMENT AND POSSIBLE THERAPIES}

The dismal prognosis of glioma patients demonstrates the need to faithfully model the formation and the biology of this tumor type to enable successful anti-glioma therapies. Immunotherapy has emerged as a promising approach to treat growing number of cancers $(107,108)$, but none has been effective in improving the survival of GBM patients $(59,109,110)$. However, researchers working on GBM believe that immunotherapy could establish successful treatment regimens where other treatments have not been successful $(111,112)$.

Genetic, histological and physiological modifications are involved in the evolution of glioma's malignancy and invasive phenotype. A good glioma animal model would enable the identification of signaling pathways which are related to tumor initiation, invasion, malignancy and therapeutic resistance. Ideally, the model should accurately resemble histologically and genetically the human disease. It should also display the cellular heterogeneity observed in glioma patients. Most glioma tumors have been previously modeled either in immunodeficient (113-115) or immunosuppressed (116) animals. However, these models have important drawbacks in terms of the lack of interactions with the adaptive immunity, which is key to fight this tumor. Also, tumors in immunocompetent mice exhibit characteristics similar to clinical pathophysiology in patients with glioma, characterized by immune infiltration and strong neovascularization, which are absent in brain tumors developed in immunodeficient mice (117).

Preclinical syngeneic murine glioma models are crucial to determine the immune response of novel therapies prior to its human clinical trial. The use of animal models of malignant glioma shed light on the composition of the TME, its influence on disease progression and outcomes, as well as on new therapeutic targets for treatment (118). The method widely 
used in glioma biomedical research is intracranial or subcutaneous injection of tumor cells like C6, 9L or GL261 into mice or rats. These syngeneic models are used to study the biology of glioma or new therapeutic agents. Also, there are other syngeneic murine glioma models, such as SMA560, GL26, CT2A, 4C8 mouse models and 9L, RG-2, F98 and CNS-1 rat glioma models which maintain the immunological interaction between the tumor cells and the host (16).

GL261 model is perhaps the most extensively used syngeneic mouse model of GBM. This model is reported to recapitulate histologic and biological characteristics of GBM (16). Furthermore, this model employs immunocompetent mice, and thus is suitable to analyze GBM tumor immunology and to perform immunotherapeutic research (119). Among the reported preclinical applications of this model, we can mention: the use of adoptive $\mathrm{T}$ cell transfers to restore and induce long-term immunity; the use of antibodies to improve antitumor $\mathrm{T}$ cell activity via augmentation of costimulatory signals; the abrogation of survival advantages of Tregs; and the enhancement of tumor immunogenicity using IL12 based gene therapy to stimulate robust cytotoxic T cell responses (119), as GL261 express unique tumor antigens which can induce a specific T cell responses (120). Moreover, this model has been employed to study the immunosuppressive effects of TGF $\beta$, which promotes Treg activity (121). Also, GL261 has been used to test the efficacy of a peptide vaccine using GL261-specific antigens and a TGF $\beta$ neutralizing antibody (1D11) (122). In another study, GL261based DC vaccines have been curative and preventive of tumor engraftment (119). Thus, these results have helped to validate GL261 as one of the model of choice for investigating immunotherapeutic treatment modalities against GBM. Likewise, GL26 model enables the study of immunotherapies. GL26 tumors express melanoma associated antigens gp100 and tyrosinase-related protein 2, both of which can be used to pulse DCs, which would in turn stimulate cytotoxic T cell-mediated robust antitumor immune response (123). Other immune-mediated strategies tested with GL26 model include Treg depletion using PC61, which is an antibody directed against CD25, one of the primary markers for Tregs (124).

SMA-560 tumors are an excellent model of anaplastic astrocytoma with low S-100 expression and high expression of glial fibrillary acid protein (GFAP) and glutamine synthetase, providing a representative model of glial tumors of astrocytic lineage (125). These tumors lack MHC Class II molecules, but do express MHC Class I at low levels which highlights their potential for antigenic recognition by traditional effector T cells (126). They also express TGF- $\beta$ which lends great value to this model (126). SMA-560 model has been used to test the efficacy of the induction of secretion of selected cytokines such as IL2, IL4, IL3, IL6 or TNFo, which resulted in an increase in MS of VM/Dk mice (126). Another study also showed that the over-expression of a soluble form of CD70 ligand in SMA-560 tumor cells, reduced tumor growth rate and increased host animal survival (127). Also, this model was used to investigate DC and CAR-T cell based therapies' outcomes for radio-resistant glioma cells (128).

Histologically, CT-2A tumors show features of high-grade astrocytomas, including pleomorphism and high cellular density, and can undergo malignant transformation with evidence of pseudopalisading necrosis (129). Compared to established glioma cell lines, CT-2A cells are significantly more proliferative and invasive (130), but less invasive than other mouse brain tumors (131). CT-2A share similarities with neural stem cells, like primary human GBMs grown ex-vivo, and express stem cell markers such as CD133, Oct and Nestin (132). Overall, the CT-2A model is considered to accurately represent several GBM characteristics including intra-tumoral heterogeneity, in vivo migratory patterns, radio-resistance, and chemo-resistance (129). By virtue of its brain tumor stem cell-like properties, the CT-2A model could provide a resource for studying the role of tumor stem cells in the immunological landscape of gliomas. Moreover, since CT-2A is deficient in PTEN and this deficiency contributes to tumor induced immunosuppression (133), this model can be utilized to devise strategies for mitigating PTEN deficiency-associated immune effects (134).

4C8-B6D2F1 tumor model was developed to address the shortcomings observed with other glial tumors (135). The 4C8 cells adopt oligodendrocytic characteristics in vitro, but convert to GFAP+ astrocytes when exposed to serum (136). Implantation of 4C8 into B6D2F1 mice produces pleomorphic, highly cellular tumors with extensive invasion into ventricles and meninges (135). They also express components of MHC I and II molecules (137). Intratumoral injections with vaccines and viruses engineered to secrete IL-12, have shown to promote significant anti-tumor activity, with detected immune cell infiltration, and minimal toxicity (138).

The RCAS/ $t v-a$ system is a model that allows the somatic transfer of oncogenes driving glioma development, enabling the development of tumor in situ. This method has been used to initiate tumors in newborn mice, by the introduction of genetic alterations into brain cells engineered to express tv-a receptor (139). Genes used to initiate brain tumors could be PDGF and Kras overexpression. These animals can then be crossed onto other genetic backgrounds in order to study the effects of particular mutations on tumor biology $(140,141)$. It has been observed that the oncogenes Kras and PDGF produce more malignant gliomas in mice with Ink4a-Arf-/- and PTEN loss backgrounds compared with those gliomas generated in wt mice, which develop lower-grade tumors $(139,142)$. Hambardzumyan D et al. described a protocol to develop gliomas in adult mice, which represent an excellent tool for studying the tumor immune microenvironment and immunotherapeutic approaches in adult gliomas $(141,143)$. Even though this model has not been widely used for the study of glioma's TME, it has been observed that, similar to what it is observed in the clinical setting, tumor malignancy of the gliomas generated with the RCAS system correlated with an influx of macrophages, which was influenced by tumor signal transducer and activator of transduction (STAT) 3 expression (144). In the same study, the authors report that STAT3 inhibition with WP1066 increased the MS of mice bearing brain tumors expressing PDGF-B + Bcl-2 (144).

Another syngeneic model to generate gliomas in situ can be achieved by the Sleeping beauty (SB) transposon system (145). This method allows high-level stable gene transfer and sustained gene expression in many somatic cell types (146). The SB transposon system, member of the Tc1/mariner class of 
transposons, is capable of recognizing inverted repeats/direct repeats (IR/DR) sites on DNA transposons and performing a cut-and-paste reaction to integrate transposable DNA segments into a host genome $(145,147)$. This method has been used to develop endogenous tumors that mimic gliomas by delivering DNA transposons that encode for the genetic lesions of interest. Our laboratory has developed a series of syngeneic GBM models using this method. For instance, we have engineered ATRXdeficient gliomas $(148,149)$, by injecting plasmids encoding SB transposase/firefly luciferase, plus other plasmids encoding for the desired genetic alterations located between IR/DR: shp53, NRASG12V, and shATRX, into the lateral ventricle of neonatal mice (148). Also, using SB transposon system, we have developed: a DIPG murine tumor model of mACVR1-G328V by injecting plasmids encoding for NRASG12V, shp53, and mACVR1-G328V (66); a mIDH1 murine tumor model by injecting plasmids encoding for NRASG12V, shp53, shATRX and IDH1-R132H (44); and a H3.3-G34R murine high grade glioma model by injecting plasmids encoding for NRASG12V, shp53, shATRX and H3.3-G34R $(67,150)$. This method has the advantage that the tumors developed can be resected, processed as a single cell suspension, and grown in vitro as neurospheres. These neurospheres can be further implanted in adult C57BL/ 6 mice.

Recently, Patel SM et al. described a method for in utero electroporation of neural stem cells to generate an in situ mouse model for DIPG tumors, a highly aggressive glioma that grows in the pons in pediatric patients (151). They used PiggyBac DNA transposon plasmids to induce the expression of different combinations of PDGFB, Pdgfra-D842V, or Pdgfra-WT, along with dominant negative $\operatorname{Trp53}$ (DNp53) and H3.3K27M expression. They report the induction of gliomas from grades IV to II, which depended on the plasmid combination (151). These tumors displayed histopathological features of the human disease and represent an invaluable tool for the modelling of the TME in DIPG, as the development of the gliomas in this model resembles their development in humans. Also, to better depict the inter-person heterogeneity in immune response and glioma genetic make-up, Aslan $\mathrm{K}$ et al., described the use of an hypermutated orthotopic glioma syngeneic mouse model, exhibiting more than 100 non-synonymous mutations per tumor exome. This model was used to study the dichotomy in the glioma response to immune-checkpoint blockade and to develop a method to try to predict the therapy outcomes by imaging MRI technique (152).

An alternative humanized mouse model system has also been developed to evaluate the efficacy of various GBM immunotherapies. Humanized models are generated by the engraftment of human cancer cell lines, or human patientderived xenograft (PDX) tumors into immunodeficient NSG mice with an HLA-matched human immune system, which is achieved by the transplantation of human PBMCs, or CD34+ hematopoietic stem cells (HSCs). Transplanted CD34+ HSCs in immunocompromised mice differentiate into human helper and cytotoxic T cells, B cells, monocytes, NK cells, and DCs (153). Humanized mice can survive months post-tumor implantation with relatively stable proportions of human cells. Human microglia/macrophage-like cells have also been developed in the brain of CD34+ HSC humanized mice (154). These models have the advantage of recapitulating tumor heterogeneity and clonal diversity, which mimics the human tumor immune microenvironment and can be used to investigate the biology of GBM $(109,155)$. Nevertheless, the humanized mouse platform is being improved in such a way that immunotherapeutic research could become more predictive. The use of humanized mouse models in GBM preclinical and clinical studies is currently limited due to the lack of knowledge and unanswered questions, such as whether humanized mice models display the clinical features of glioblastoma patients. For instance, Ashizawa T. et al., investigated the efficacy of the anti-PD-1 antibody using humanized NOG-dKO mice, generated by implanting human PBMCs and GBM cell line U87 (156). In this study, there was no rejection of the human glioma cells or the PBMCs, and T-cell and NK-cell anti-tumor immune responses were detected, thus constituting an interesting model to evaluate the effect of immunotherapeutic agents against glioma. Despite these advantages, humanized mouse models are partial in maintaining the cellular and mutational diversity of parental tumors and entail an extended generation time (157, 158). Patient-derived glioblastoma organoids (GBOs) that recapitulate the histological features, cellular diversity, gene expression, and mutational profiles of their corresponding parental tumors have recently been developed and biobanked. When GBOs are transplanted into adult rodent brains, they show rapid, aggressive infiltration and high reliability (157).

While there is no perfect murine model to study immunotherapies for glioma, syngeneic tumor models in immunocompetent mice represent a valuable resource for this purpose. The transplantable models presented are convenient because tumor location and growth can be better predicted and thus, the testing of different therapies and their relationship with the immune system can be more easily studied. Although orthotopic xenografts retain some of the human GBM features and are considered to be a useful model for therapeutic studies (159), it lacks the proper immune environment due to the use of immunocompromised mice, which is a drawback for the study of tumor immunology and anti-tumor immune-stimulatory therapies.

\section{STRATEGIES TO OVERCOME IMMUNOSUPPRESSIVE MICROENVIRONMENT: CURRENT THERAPEUTIC MODALITIES UNDER CLINICAL TRIAL AND UNDER PRE- CLINICAL INVESTIGATION}

\section{Immune Checkpoint Blockade}

Immune checkpoints (IC) are negative regulators of the immune system that maintain self-tolerance, avoid autoimmunity and adjust the extension and duration of the immune responses to prevent tissue damages (160). The mechanism involves the 
interaction between IC receptors with its ligands, acting as a natural feedback loop that inhibits and reduces inflammation. Likewise, cancer cells could express IC ligands as a way to evade immune-mediated elimination. Examples of these immunomodulatory molecules, which are negative regulators of $\mathrm{T}$ cell activation and function, include the cytotoxic $\mathrm{T}$ lymphocyte antigen 4 (CTLA-4), the programmed cell death 1 (PD-1) and its ligand PD-L1, TIM-3, the enzyme indoleamine 2,3-dioxygenase (IDO), $\mathrm{V}$-domain Ig suppressor of $\mathrm{T}$ cell activation (VISTA), killer-cell immunoglobulin-like receptor (KIR), TIGIT, B and T lymphocyte attenuator (BTLA) and LAG-3. Amongst them, CTLA-4, IDO and PD-1/PD-L1 are the most studied molecules inhibitors for which have been developed and evaluated in preclinical and clinical assays (160).

First attempts in developing IC inhibitors (ICIs) were focused in CTLA-4 molecule. CTLA-4 is a co-inhibitory receptor present on the surface of Treg that was discovered in the late 80 's (161). CTLA-4 has the B7 family of proteins (B7-1 or CD80 and B7-2 or CD86) as natural ligands, which are found at the surface of antigen presenting cells (APC). Even though CTLA-4 shares structural and biochemical similarities with CD28, a potent costimulatory receptor of T cells, CTLA-4 and CD28 have opposite immunoregulatory functions. Binding of CTLA-4 to B7 ligands has a 20-100 fold higher affinity than CD28, so when both are present, $\mathrm{T}$ cell activation is prevented and cytokine production switches to an immunosuppressive pattern, i.e. IL-10, TGF $\beta$, and indoleamine (162).

Despite the lack of correlation between CTLA-4 ligand expression and a specific cancer cell type and the fact that Ctla-4-knockout mice models predicted lethal autoimmune phenotypes, it was shown that CTLA-4 inhibition produced antitumoral responses in preclinical cancer models (163). These preclinical studies showed promising results in some immunogenic tumors, using antibodies as a single agent or in combination with other agents that stimulated immune responses after tumor implantation, in the case of poorly immunogenic cancer models (163). Therefore, the development of fully humanized anti-CTLA-4 antibodies led to clinical testing of Ipilimumab and Tremelimumab. The first clinical study of CTLA-4 antibody treatment was performed in patients with advanced melanoma that were not responding to conventional therapy (164). Ipilimumab is a IgG1 monoclonal antibody that blocks the CTLA-4/CD80-CD86 interaction on APCs and T cells, promoting co-stimulatory binding of CD28 to CD80/CD86 (165). On the other hand, Tremelimumab is a monoclonal IgG2 antibody with a similar CTLA-4 blocking mechanism; but it only received orphan drug designation from the FDA for malignant mesothelioma (166).

Several pre-clinical trials evaluated the effects of CTLA-4 inhibition in GBM mouse models, showing differences in the outcomes depending on the tumor model evaluated. CTLA-4 blockade alone resulted in $80 \%$ of long survivors and abrogated Treg expansion in SMA-560 tumor-bearing mice (167). However, in other studies, the efficacy of this treatment was much lower, with 40 to $15 \%$ long term survivors $(168,169)$, or did not elicit antitumor efficacy (9). A significant challenge to effectively asses the efficacy of ICIs in GBM is to develop better pre-clinical animal models. In this sense, the SB28 GBM model recapitulate human GBM features, like low mutational levels and loss of MHC-I expression (170). Besides these technical issues, the sole inhibition of CTLA-4 in the immunologically suppressed microenvironment of GBM may not be effective to trigger a successful antitumoral immune response since this receptor is only present on $\mathrm{T}$ cells (171). In fact, our previous findings indicate that although the treatment with anti-CTLA-4 in GL26 GBM-bearing mice did not elicit antitumor effects, it boosted the efficacy of immune-stimulatory TK+Flt3L gene therapy (9). Moreover, even though preclinical data of CTLA-4 inhibition showed potential effects for GBM treatment, several adverse effects occur through a rapid and nonspecific activation of the immune system. In this regard, a Phase 1 clinical trial of Nivolumab (anti-PD-1) alone or in combination with Ipilimumab in patients with recurrent GBM showed no differences in OS but higher toxicity with the addition of antiCTLA-4 to the treatment (172).

PD-1, which was first identified in 1992 as a putative proapoptotic receptor (173), plays a major role in limiting immune response and regulates $\mathrm{T}$ cell biology (174). While CTLA-4 acts early on $\mathrm{T}$ cell activation inhibition in the lymph nodes, PD-1 immune checkpoint controls the activity of $\mathrm{T}$ lymphocytes in peripheral tissues (175). PD1 ligand 1 (PD-L1; also known as B7$\mathrm{H} 1$ and CD274) and PD-L2 (also known as B7-DC and CD273) serve as ligands for PD-1. They are present constitutively on resting $\mathrm{T}$ cells, dendritic cells, $\mathrm{B}$ cells, natural killer cells and macrophages, and can be induced in non-haematopoietic tissues by pro-inflammatory cytokines $(176,177)$. Specifically, tumor cells can express these ligands, protecting them from immune system eradication (178). For instance, the term "innate immune resistance" makes reference to $P D L 1$ gene amplification or the upregulation of PD-1 ligands by constitutively active signalling pathways on tumor cells (179-182). On the other hand, the "adaptive immune resistance" situation makes reference to PD$\mathrm{L} 1$ expression by tumor cells in response to IFN $\gamma$ release by $\mathrm{T}$ cells $(183,184)$.

The interaction PD-1/PD-L1 provokes effector $\mathrm{T}$ cells cell cycle arrest and the down-regulation of cell survival molecules like Bcl-XL, the dephosphorylation of ZAP70, and the phosphorylation of PI3K by the recruitment of SHP1 and SHP2 phosphatases (185). PD-1/PD-L1 axis disruption was thought to be a promising approach to overcome $\mathrm{T}$ cell inhibition and to promote an antitumoral immune response. In this regard, numerous studies have shown successful results in the treatment of metastatic melanoma $(186,187)$, Non-small cell lung cancer (188) and renal cell carcinoma (189). Preclinical studies using orthotopic mice models of GBM showed that PD-1 inhibition promoted NK cytotoxic effects against cancer cells when used as a single agent $(190,191)$ or in combination with radiotherapy (192). However, most clinical trial studies using anti-PD-1/PD-L1 monotherapy have shown limited efficacy in GBM patients (193).

Checkmate 143 was a Phase III clinical trial evaluating ICIs (Ipilimumab + Nivolumab) in GBM patients. It was concluded 
that Nivolumab as monotherapy was better than the combination, due to increased adverse effects when combined with Ipilimumab, and a significant increase in OS in comparison to the current therapy with Bevacizumab was not observed (194). In the case of PD-L1 inhibitors, a Phase 1 clinical trial of Atezolizumab as monotherapy in patients with recurrent GBM have shown no improvements in survival (195).

In conclusion, anti-PD-1 immunotherapy has been extensively evaluated in mouse models, and in clinical trials as monotherapy or in combination with other treatments, offering novel approaches for the treatment of GBM (Table 1) (12). Additionally, anti-PD-L1 immunotherapy has also been well evaluated in clinical trials (Table 2). Although the efficacy of ICIs as single agents has shown no satisfactory results in GBM, it is necessary to evaluate their efficacy as complements of other active immunotherapeutic strategies, such as vaccines and/or immune-stimulating gene therapies, which promote $\mathrm{T}$ cell infiltration, the subsequent IFN $\gamma$ production and PD-1/PD-L1 upregulation.

IDO is an enzyme with an essential role in the catabolism of tryptophan (Trp) into different metabolites, like kynurenines (Kyn). Although it is not considered as a classical checkpoint, it is included in this group of molecules because it has powerful immunosuppressive properties $(196,197)$. IDO expression in the context of tumor immunity has been associated to cancer and immune cells (198). IDO contributes to immunosuppression activities by increasing Kyn levels and depleting Trp, which inhibit effector $\mathrm{T}$ cells and NK cells, and promotes Treg proliferation (198). This enzyme has been shown to be upregulated in almost all GBM patients (199) and its high expression correlates with malignancy (200). In this sense, a pre-clinical study of TMZ in combination with an IDO inhibitor showed tumor growth reduction and an increase in long-term survival of mice with GBM (201). Encouraging preclinical results led to several clinical trials with IDO1 inhibitors, but unfortunately administration as single agent did not show significant antitumoral activity. Nowadays, several clinical trials are being conducted in order to test IDO inhibition efficacy, in combination with TMZ and radiotherapy (NCT03532295, NCT02502708 and NCT04049669). Similarly, another trial tested the combination of an IDO inhibitor (INCB024360) with Nivolumab, Anti-GITR MAb and Ipilimumab in patients with recurrent GBM (NCT03707457). However, after a failed Phase III trial in melanoma, with no differences in progression free survival (PFS) or OS, it was proposed that IDO is not an appropriated target in cancer (202). However, it is possible that more effective and specific inhibitors need to be developed in order to successfully block IDO pathway in cancer (203).

Trp degradation to Kyn by IDO1 and TDO2 provokes Trp starvation, which causes the subsequent activation of general control nonderepressible 2 (GCN2), decreasing general protein production. IDO-activated GCN2 also affects $\mathrm{T}$ cells proliferation and effector function, by inhibiting fatty acid synthesis, promoting T-regs activation (204), Platten, 2012 $\# 122$ \}. In this sense, Trp degradation has been recognized as an important microenvironmental factor with immunosuppressive properties. Particularly, the IDO/TDO-Kyn-AhR enzymatic cascade has emerged as an interesting pathway to develop novel therapeutic strategies and overcome tumour immune scape in GBM. In this regard, besides several IDO inhibitors that are being tested in preclinical and clinical trials, Kyn has been shown to be an interesting target due to its aryl hydrocarbon receptor (AhR) agonist activity. AhR activation promotes the generation of immunetolerant DCs and T-regs (205). Thus, the approach of depleting extracellular Kyn has shown promising efficacy in mouse models. Engineered KYNase catalyses the synthesis of anthranilic acid from Kyn, promoting effector T cell infiltration into the tumour (206). Finally, several AhR antagonists are being tested in preclinical studies (207). However, due to their broadly effects inhibiting any AhR ligand (endogenous and exogenous), development of antitumoral AhR therapies is in early stages (207). In this sense, it remains to be elucidated if this approach will show anticancer activity by acting on cancer cells or by modulating immune responses, and if they achieve optimal pharmacokinetic/ pharmacodynamic profiles (204).

\section{Macrophage Reprogramming}

The heterogeneous microenvironment of glioblastomas contains an enriched proportion of non-tumor cells which characterize the TME. Although the quantity of lymphocytes is very low, the tumor-associated macrophages (TAM) have been described as one of the major populations of GBM's TME. TAM comprises two main subpopulations, the microglia ( $\mathrm{MG}$ ) and the monocyte-derived macrophages (MDM) (208, 209). MGs are the resident immune cells of the central nervous system specialized to monitor and respond to pathogens or injuries (210) and MDMs are peripheral bone marrow derived cells that infiltrate the TME. Despite different origins, these two populations function as immune-suppressed cells of the TME which diminish $\mathrm{T}$-cell response and promote tumor progression and invasion (209). Different studies have shown that the protumorigenic role of TAM is promoted by their interaction with glioma cells through mutual paracrine signaling. Different released factors have been involved in TAM-GBM interaction and the shift of TAMs to an M2 phenotype, which is characterized by anti-inflammatory properties and reduced phagocytic activity. Several studies have demonstrated that CSF1 could act as MG chemoattractant and that TAM released factors, such as the epidermal growth factor (EGF), TGFB1, IL10, TNF, MMP14, MMP2, can promote GBM migration and invasion (211-213). Due to the immune-suppressing role of TAM in tumor progression, this population became a novel target for antitumor immunotherapies (213).

Different strategies have been focused on the impairment of macrophage tumor recruitment and on the reprogramming of phagocyte innate immune surveillance functions of MDM and MG (Figure 1).

Recent studies have shown that the CSF1 ligand is expressed in glioma cells and TAM. The CSFR1R is only expressed on macrophages (214). Inhibition of CSF1R using the blood-brain barrier permeable compound BLZ945, significantly decreased tumor growth and extended survival in a mouse model of GBM and patient-derived xenografts models. Treatment efficacy was 
TABLE 1 | PD-1 inhibitor treatments approved by the FDA and in clinical testing for GBM patients.

Clinical trials investigating the use of ICls for treatment of GBM

\begin{tabular}{|c|c|c|c|c|c|}
\hline Drug & Target & Name & Year & $\begin{array}{l}\text { Clinical } \\
\text { Phase }\end{array}$ & Arms \\
\hline \multirow[t]{40}{*}{ PD-1 } & \multirow[t]{18}{*}{ Nivolumab } & Neoantigen-based personalized Vaccine & Actual Study & I & Arm A: NeoVax + Nivolumab (at progression) \\
\hline & & $\begin{array}{l}\text { Therapy in Patients with Newly Diagnosed, } \\
\text { Unmethylated GBM }\end{array}$ & $\begin{array}{l}\text { October } 31 \\
2018\end{array}$ & & Arm C: NeoVax + Nivolumab (at Cycle 1) \\
\hline & & & Actual Primary & & \\
\hline & & & Completion Date: & & \\
\hline & & & Completion Date: & & \\
\hline & & & $\begin{array}{l}\text { February } 26 \\
2021\end{array}$ & & \\
\hline & & GMCl, Nivolumab, and Radiation Therapy in & Actual Study & I & Arm A: MGMT Unmethylated patients; AdV-TK injection into \\
\hline & & $\begin{array}{l}\text { Treating Patients with Newly Diagnosed High- } \\
\text { grade Gliomas }\end{array}$ & $\begin{array}{l}\text { Start Date: } \\
\text { February } 27\end{array}$ & & $\begin{array}{l}\text { resection cavity, valaciclovir } 14 \text { days, radiation after } 8 \text { days, } \\
\text { TMZ after valaciclovir, Nivolumab every } 2 \text { weeks to } 52 \text { weeks }\end{array}$ \\
\hline & & & $\begin{array}{l}\text { February 28, } \\
2021\end{array}$ & & \\
\hline & & & Estimated Study & & \\
\hline & & & Completion Date: & & \\
\hline & & & $\begin{array}{l}\text { February 28, } \\
2021\end{array}$ & & \\
\hline & & Translational Study of Nivolumab in & Actual Study & $\|$ & Arm A: Nivolumab + Bevacizumab in patients not undergoing \\
\hline & & Combination with Bevacizumab for Recurrent & Start Date: & & salvage surgery \\
\hline & & Glioblastoma & $\begin{array}{l}\text { October 1, } 2018 \\
\text { Estimated }\end{array}$ & & $\begin{array}{l}\text { Arm B: Nivolumab + Bevacizumab in patients not undergoing } \\
\text { salvage surgery }\end{array}$ \\
\hline & & & Primary & & \\
\hline & & & Completion Date: & & \\
\hline & & & February 1, 2022 & & \\
\hline & \multirow[t]{22}{*}{ Pembrolizumab } & \multirow[t]{7}{*}{$\begin{array}{l}\text { Combination Adenovirus + Pembrolizumab to } \\
\text { Trigger Immune Virus Effects (CAPTIVE) }\end{array}$} & $\begin{array}{l}\text { Study Start Date: } \\
\text { June } 2016\end{array}$ & $\|$ & $\begin{array}{l}\text { Intratumoral DNX-2401 (a genetically modified oncolytic } \\
\text { adenovirus) followed by IV Pembrolizumab }\end{array}$ \\
\hline & & & Estimated & & \\
\hline & & & Primary & & \\
\hline & & & Completion Date: & & \\
\hline & & & December 2020 & & \\
\hline & & & Estimated Study & & \\
\hline & & & $\begin{array}{l}\text { Completion Date: } \\
\text { June } 2021\end{array}$ & & \\
\hline & & Laser Interstitial Thermotherapy (LTII) & Actual Study & $1 / 11$ & Arm A: IV Pembrolizumab 7 days pre-surgery with LITT \\
\hline & & Combined with Checkpoint Inhibitor for & Start Date: & & Arm B: IV Pembrolizumab 14 days post-surgery with LITT \\
\hline & & Recurrent GBM & $\begin{array}{l}\text { November 29, } \\
2017\end{array}$ & & Arm C: IV Pembrolizumab 35 days post-surgery with LITT \\
\hline & & & Estimated & & \\
\hline & & & Primary & & \\
\hline & & & Completion Date: & & \\
\hline & & & December 2020 & & \\
\hline & & & Estimated Study & & \\
\hline & & & $\begin{array}{l}\text { Completion Date: } \\
\text { January } 2021\end{array}$ & & \\
\hline & & PVSRIPO and Pembrolizumab in Patients With & Estimated Study & I & Single Arm: PVSRIPO intratumoral infusion followed by \\
\hline & & Recurrent Glioblastoma & Start Date: & & intravenous Pembrolizumab 14 to 28 days later, and every 3 \\
\hline & & & September 2020 & & weeks, thereafter \\
\hline & & & Estimated & & \\
\hline & & & Primary & & \\
\hline & & & Completion Date: & & \\
\hline
\end{tabular}


TABLE 1 | Continued

Clinical trials investigating the use of ICls for treatment of GBM

\begin{tabular}{lccc}
\hline Drug Target Name & Year & $\begin{array}{l}\text { Clinical } \\
\text { Phase }\end{array}$ & Arms \\
\hline
\end{tabular}

March 2023

Estimated Study

Completion Date:

March 2023

TABLE 2 | PD-L1 inhibitor treatments approved by the FDA and in clinical testing for GBM patients.

\begin{tabular}{|c|c|c|c|c|c|c|}
\hline \multicolumn{7}{|c|}{ Clinical trials investigating the use of ICls for treatment of GBM } \\
\hline PD-L1 & Avelumab & NCT03047473 & $\begin{array}{l}\text { Avelumab in Patients with } \\
\text { Newly Diagnosed } \\
\text { Glioblastoma Multiforme }\end{array}$ & $\begin{array}{l}\text { Actual Study Start Date: March 10, } 2017 \text { Estimated Primary } \\
\text { Completion Date: September } 2022 \text { Estimated Study } \\
\text { Completion Date: September } 2022\end{array}$ & $\|$ & $\begin{array}{l}\text { Addition of Avelumab to } \\
\text { standard therapy of TMZ } \\
\text { and radiotherapy }\end{array}$ \\
\hline
\end{tabular}

related to M2 macrophage polarization inhibition, but not TAM depletion in tumor treated mice. Molecular analysis of TAM showed that this population had an inhibited expression of some M2 polarization markers, such as Arg1, F13a1, Mrc1, and Adm (215). Although, different inhibitors such as BLZ945, RG 7155,
PLX339 have been tested in clinical trials, blocking of CSFR1 remains challenging and requires further studies.

TAM survival is maintained by factors released by glioma cells, such as interferon- $\gamma($ IFN- $\gamma$ ) and granulocyte-macrophage colony stimulating factor $(215,216)$.

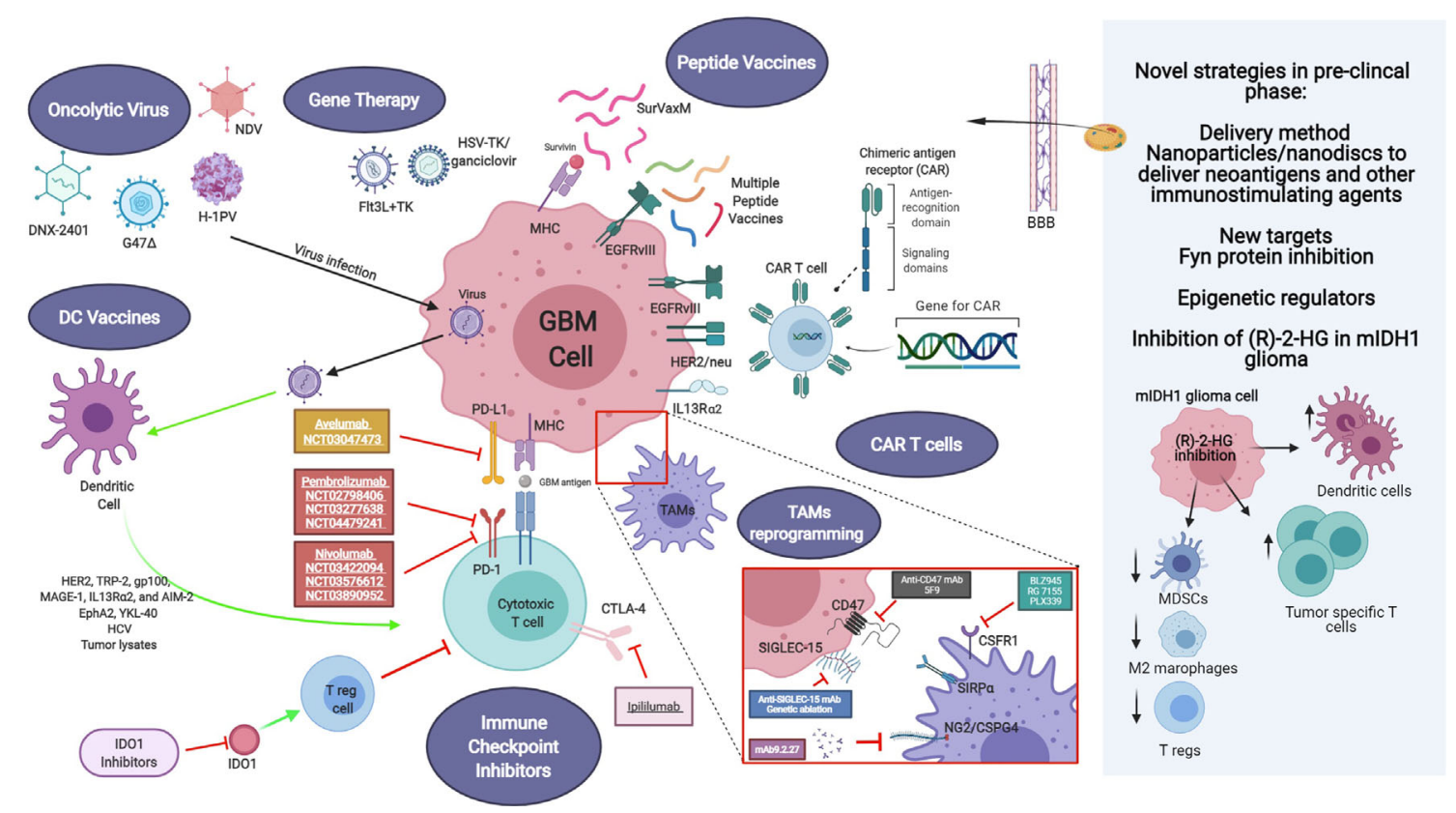

FIGURE 1 | Current and novel immunotherapeutic strategies for GBM treatment under pre-clinical and clinical investigation. Current immunotherapeutic strategies in GBM include oncolytic viruses that can destroy glioma cells through immunogenic cell death without affecting non neoplastic brain cells, TAM reprogramming and the use of CAR T cells. Activation of immune checkpoint ligands such as PD-1, CTLA-4, and IDO can help tumor cells to escape immune surveillance. Thus, inhibition of them can effectively inhibit glioma progression and improve the response to other active immunotherapeutic strategies, such as DC vaccines and immunostimulant gene therapy. GBM antigens, including IL-13R $\alpha 2$, HER2/neu and EGFRvIll are present in tumor cells. These tumor-associated antigens are targets of genetically modified CAR-T cells or peptide vaccines. Also, novel strategies are being studied currently in the pre-clinical setting, addressing more efficient ways to cross the blood-brain barrier (BBB), such as nanodiscs, and the modulation of the activity of novel targets. Created with BioRender.com. 
The combined treatments of CSFR1 inhibitors with PD-1 or PDL-1 monoclonal antibody are promising avenues under investigation in clinical trials (216). Also, the combination of triple therapy using checkpoint inhibitors (anti-CTLA-4 and anti-PD-1), and immune-virotherapy showed effective M1 polarization of macrophages and tumor eradication (217). Other combinational therapy approach inhibiting the Neuroglial-2/Chondroitin sulfate proteoglycan-4 (NG2/CSPG4) axes using the antibody mAb9.2.27 together with activated NK cells in preclinical animal models of gliomas decreased tumor growth, by increasing recruitment of CCR2low MDM to the TME and by amplifying ED1 and MHCII expression on MG (218).

Likewise, other studies showed that therapies using dual inhibitors of VEGF and Angiopoietin-2 (ANG-2) axes led to modifications in TAMs. A2V bi-specific antibody or dual therapies utilizing Cediranib and MEDI3617, reprogramed macrophages to antitumor M1 phenotype, inhibited TAM recruitment and delayed tumor growth and progression $(219,220)$.

Further research studies demonstrated that CXCR4 signaling is involved in the recruitment of TAM to the TME. Inhibition of this axis using the clinically approved drug AMD3100 prevents BMDCs infiltration, tumor revascularization, and abrogate tumor recurrence (218). Moreover, a recent phase I/II clinical trial study showed positive results in macrophage recruitment inhibition and local control of tumor recurrences after irradiation therapy using a reversible CXCR4 inhibitor Plerixafor (221).

Glioma cells redirect macrophages activating signals to a proinflammatory M2 state. This strategy has been related to the overexpression of Spp1 (secreted phosphoprotein 1 or osteopontin) and Mgfe8 (milk fat globule-EGF factor 8 or lactadherin) on glioma cells and human glioblastoma tissue, which prompt M2 reprogramming of MG as a result of integrin signaling activation. Furthermore, downregulation of Spp1 and Mgfe8 within glioma cells inhibits the amoeboid transformation of myeloid cells and redirect M2 microglia/ macrophages phenotype impairing glioma growth (222).

The latest strategies developed have been related to the targeting of CD47/SIRPA (signal regulatory protein alpha) pathway. CD47 is a transmembrane protein overexpressed in glioma cells that binds to the receptor SIRPA on the surface of monocytes/macrophages and MG cells inhibiting phagocytic functions and allowing tumors to escape the innate immune surveillance. Transcriptomic analysis of human gliomas has shown that high expression of CD47 correlates with overall survival, which makes CD47 a novel prognostic marker (223, 224). The mechanism of activation of CD47/SIRPA includes the activation of ITIM (immune-receptor tyrosine-based inhibitory motif) and subsequent signalling through the activation of PTPN6 (protein-tyrosine phosphatase non-receptor type 6) and PTPN11, inhibiting phagocytosis (225). Moreover, preclinical studies based on orthotopic glioma models showed that blocking CD47 using antibodies decreased tumor growth and enhanced animal survival (223). Even though the major role of CD47 inhibition has been attributed to peripheral macrophage recruitment, Hutter, G. et al also demonstrated its effect on resident microglia. Using mouse glioma models which enable the differentiation of genetically labelled MDM (Ccr2 RFP) and MG (Cx3crl GFP), they showed that microglia associated tumor cells increase tumor cell phagocytosis in response to CD47/SIRPA axis inhibition (226). This data indicates that enhancement of MDM and MG phagocytosis phenotype is a promising avenue for glioma treatment. Recent clinical trial studies using 5F9, a CD47 inhibitor, on other solid tumors showed a positive response in combination with other anticancer treatments (227).

Another feature of malignant transformation in glioma is the protein over-glycosylation ended by charged sialic acid in glioma cells, which constitutes novel target. SIGLEC (sialic acid-binding immunoglobulin-like lectin) proteins (14 different identified variants) are receptors of sialic acid and they are mainly present on immune cells (TAMs) acting as negative regulators of phagocytosis. SIGLEC receptor activates immunosuppressive signals after binding to sialic acids through the same signalling pathways activated in the CD47/SIRPA axe as discussed above $(213,228,229)$. Examination of the sialic acid/SIGLEC pathway has demonstrated that genetic and antibody ablation of SIGLEC15 expands anti-tumor immune response and obstructs tumor growth in mouse glioma models (230).

In summary, these studies show that regulation of TAM recruitment to the tumor mass or re-education to a phagocyte phenotype contributes to the anti-tumor response and inhibition of glioma progression. Due to the diversity and plasticity of TAMs, a better understanding of the mechanisms involved in TAMs recruitment and reprogramming remain a challenge to target these immune modulators of the TME for treatment. Combination of conventional therapies, immune checkpoint inhibitors together with TAMs regulation appears to be a promising alternative to improve glioma immunotherapy and halt glioma progression.

\section{Therapies Aiming at the Stimulation of the Immune System to Develop Anti-Tumor Specific Immune Response}

An additional group of immunotherapies are aimed at inducing the development of antitumor specific responses, i.e. mediated by specific T-cells or antibodies production. These therapies were discussed in detailed before, and it is not the purpose of this manuscript to review them on detail. Anti-tumor specific response-inducing therapies can be summarized in:

- Oncolytic virus-mediated therapies, where oncolytic viruses are targeted to the tumor cells to cause Immunogenic cell death (ICD), stimulating the release of tumor-associated antigens (TAA) and damage-associated molecular patterns (DAMPs), which help to overcome the immunosuppressive tumor microenvironment (231). In this way, ICD induces the recognition of tumor cells by the immune system and the development of long-term immunity (232). Furthermore, OVs induce antiviral innate immune responses triggered by pathogen-associated molecular patterns (PAMPs) (231). Additionally, OVs can be genetically engineered to deliver immunotherapeutic transgenes or to increase their tumor 
selectivity, enhancing their potential for oncolytic immunotherapy (231-246).

- Suicide gene therapies, which comprises the delivery of genes encoding a conditionally cytotoxic enzyme that converts a non-toxic prodrug into a cytotoxic compound. In this way, transduced tumor cells are destroyed, sparing normal cells (247). The most evaluated suicide gene therapy for the treatment of GBM is HSV- thymidine kinase (TK) plus systemic administration of ganciclovir (GCV) (247).

- Peptide vaccines, where the main objective is to inhibit cancer progression or relapse, by producing humoral (tumor-specific antibodies) or cellular (cytotoxic $\mathrm{T}$ cells activation) responses against tumors $(20,248)$.

- Dendritic cells (DC) vaccines. DCs are professional antigen presenting cells (APCs), which function is to recognize, process and present antigens to $\mathrm{T}$ cells in the context of the major histocompatibility complex (MHC) I and II, in order to activate $\mathrm{T}$ cells and subsequently the adaptive immune response (12). Moreover, DCs are able to secrete pro and anti-inflammatory cytokines that modulate the tumor microenvironment. Autologous DCs can be loaded ex vivo with tumor antigens, peptides, tumor lysates, viral antigens, GSC or mRNA, among others, and then be administered back to patients as an antitumor vaccine $(8,249)$. These autologous DCs are usually differentiated from autologous monocytes by the incubation with specific cytokines (12).

- CAR T therapy. Chimeric antigen receptors (CARs) are recombinant receptors for specific targets found on cancer cells. They are designed to redirect the specificity and function of patient-derived cytotoxic $\mathrm{T}$ cells, which are ex vivo genetically engineered to express the CAR and re-infused to the patient $(186,250,251)$.

\section{INFLUENCE OF GENETIC ALTERATIONS PRESENT IN GLIOMA SUBTYPES ON THE RESPONSE TO IMMUNOTHERAPIES}

Although the use of immune therapies to treat gliomas is still in its early stages, i.e., in research and trial phases, the knowledge accumulated in the field in CNS tumors and other solid cancers indicate that the genetic makeup of the tumor is a predictive factor of the efficiency of the immune therapies. Not only the genetic information can predict if a treatment is likely to generate response or not, but also the genetic alterations present in certain subtypes of tumors can be exploited to devise tailored immunotherapies. In solid tumors, it was observed that the mutational load is a positive predictive factor of response to immunotherapy. A significant proportion of gliomas have mutations associated with DNA repair defects and genetic instability (252). As a consequence of this, higher mutational burden, has been observed, particularly in pediatric HGG patients with DNA repair-related germline mutations (252). Although a recent study found no correlation between mutational load and response to immune checkpoint inhibition in glioma (253), it is likely that the treatment in this study was inefficient due to the poor penetrance of the immune checkpoint inhibitors to the brain (254). In this respect, a patient with Lynch syndrome (a genetic condition related with mismatch DNA repair deficiency) who developed an IDH-mutant glioblastoma was treated with a PD-1 inhibitor (Nivolumab), remaining free of recurrence for 5 years (255).

Recent studies have described the peculiarities of the immune compartment in gliomas, which is strongly immunosuppressive and enriched in myeloid suppressor cells and exhausted and regulatory T-cells (209). Recently, it was demonstrated that the interactions between tumor cells and the immune microenvironment are influenced by the genetic alterations of the tumors. For instance, some studies reported that IDH mutations induce epigenetic changes that lead to establishing an immunosuppressive TME $(94,100)$. However, work from our team reported that infiltrating immune myeloid cells in the mutant-IDH TME are devoid of immunosuppressive properties. This highlights that it is not only important to identify the presence of a particular immune cells population using defined molecular markers, but also to assess the functional activity of these cells, to be able to describe the characteristics of the TME (15). In addition, it has been reported that mutant-IDH glioma cells express lower PD-L1 levels due to epigenetic reprogramming, suggesting a less immunosuppressive environment. All this information is pivotal to devise therapeutic approaches, e.g., the concept of combining mutant-IDH inhibitors (to revert the suppressive TME) with immunotherapies. However, considerable work still needs to be done in regards to the genetic and functional characterization of immune cell populations in the TME of gliomas. Single-cell RNA-seq allows the identification of different immune cells within the glioma TME, and can inform on whether certain molecular subtypes of glioma have more immuneactive or immune-suppressive environments. Another type of technologies that can shed light into the characteristics of the immune populations within glioma TME are the studies performed in de novo genetically engineered animal models, which can be developed in immunocompetent mice and allow to dissect the effect of particular genetic alterations in the immune TME $(15,44,148)$. This type of studies will also help devising tailored immunotherapies for specific gliomas. For instance, a group of NF1-mutant low grade gliomas was demonstrated to be associated with immune activation, increased cytolytic T-cell infiltration and neoantigens production, and this group might benefit from immunotherapies (256).

Another area where immunotherapies benefit from the knowledge of the glioma genetic makeup is on the development of CAR-T therapies or peptide vaccines. CAR-T therapies require the identification of targets that are expressed on the surface of the tumor cells and that are not expressed in normal cells. Interleukin13 receptor $\alpha 2$ (IL-13R $\alpha 2)$ was identified as a glioma specific marker, and CAR-T therapy with cells targeting this protein was evaluated in a clinical trial (257). The preliminary results of this study on a single patient reported glioma regression, but development of therapy resistance associated to the emergence of (IL-13R $\alpha 2$ ) negative cells. Additionally, histone K27M-mutant cells show consistent expression of GD2, and its CAR-T-mediated targeting was efficient in K27M xerograph models (258). These 
studies provide the foundation on future directions to develop efficient immunotherapies for glioma. CAR-T cell therapies. The identification of multiple cell surface markers with minimal offtarget effects for the different molecular subtypes of gliomas is essential to target tumors and prevent antigen escape-associated resistance. In this regard, the recent genomic analysis of gliomas has led to the identification of clonal mutations that drive the different molecular subtypes. For example, IDH1/2 mutations in adult gliomas and histone $\mathrm{H} 3.1$ and $\mathrm{H} 3.3$ mutations in pediatric high grade gliomas were shown to be clonal for their respective subtypes, and developing therapies targeting these genetic alterations would reduce the risk of antigen-escape.

The epigenetic alterations induced by driver mutations such as those in IDH1/2 and H3.1 and H3.3 histones may also induce DNA repair deficiencies and/or genetic instability, and this can be associated with more immune reactive tumors. For example, cells more susceptible to DNA damage, such as H3.3-G34R mutant cells (259), undergo immunogenic cell death (ICD) upon DNA damaging conditions, which can revert the immune-suppressive TME. For this reason, acknowledging the susceptibility of the different glioma molecular subtypes to different treatments to induce ICD. For example, HDAC inhibitors were shown to target K27M HGG (260), and other tailored therapies are being explored for other subtypes (252), but the potential combinations of treatments inducing ICD and immunotherapies remain unexplored.

In summary, it is clear that the genetic alterations present in the different glioma molecular subtypes are determinant of the efficacy of immunotherapies possibilities and responses, and that the evolving information of each glioma subtype will provide opportunities for novel tailored immunotherapies.

\section{NOVEL TARGETS AND STRATEGIES TO STIMULATE ANTI-GLIOMA IMMUNE RESPONSE}

In this section, we aim to discuss about the latest glioma targets and anti-tumor strategies being studied in the pre-clinical setting (Figure 1).

\section{Fyn Inhibition as a Target to Enhance Immune Response and Prevent Tumor Progression}

Despite current advances in the molecular characterization of gliomas and novel therapies to target the tumor immune microenvironment, treatment of glioblastoma remains elusive (34, 261). Latest studies indicate that glioma infiltrating myeloid cells inhibit the anti-glioma immunity and enhance tumor progression and thus, the identification of the connections between tumor cells and the tumor immune suppressive microenvironment could open innovative treatment options $(9,262)$. Fyn, a non-receptor tyrosine kinase member of the Src family kinases (SFK), has recently emerged as a novel regulator of the tumor immune microenvironment during glioma development (20, 248). Fyn regulates several cellular functions in normal physiology and is deregulated in different cancers (263-265). It has been shown that Fyn displays important functions related to the immune system modulation, regulating the activity of T cells $(266,267)$; and in the development of the CNS, regulating the migration and adhesion of neurons $(268,269)$. Previous studies on Fyn's role in cancer, including glioma, show that Fyn is activated via NRAS dependent and independent pathways through the oncogenic receptors EGFR, PDGFR, HGF/MET or RTK/RAS/PI3K to increase cell migration, proliferation and reduce cell death (270-272). These growth factor receptors are the most common mutated driver genes in GBM tumorigenesis $(34,261)$. Even though Fyn is mutated in a very low percentage of human gliomas (0.1-0.4\%), it has been shown that it is overexpressed in higher grade mouse and human gliomas $(20,270)$.

Until recently, Fyn has been best known by its cellautonomous functions. The majority of in vitro studies showed that pharmacological inhibition and genetic downregulation of Fyn in glioma cells decreased cell proliferation and migration $(265,270,273,274)$. However, in vivo studies had been inconclusive (275). Recently, Comba et al. demonstrated not only the effects of Fyn in increasing glioma cell proliferation and migration, but also an unusual cell-non-autonomous role of Fyn inhibiting the anti-glioma immune response (20). RNA-Seq and network bioinformatic analysis of the tumor transcriptomic landscape on glioma mouse model tumors indicated that Fyn's biological effects were related to the immune microenvironment. Using diverse genetically engineered immune-competent mouse glioma models, the study shows that genetic downregulation of Fyn increases survival and decreases glioma growth and progression. Interestingly, Fyn knockdown tumors generated in immune deficient mice (NSG, CD4-/- and CD8-/-) exhibited no differential effects on tumor growth and survival, demonstrating the relevance of the immune response in the progression of these tumors. The mechanistic analysis showed that Fyn depletion reduces the expansion of the immune suppressive myeloid cells (MDSCs) in the TME, including monocytic-MDSCs (CD45+, CD11b+, Ly6Chi, Ly6G-) or polimorphonuclear-MDSCs (CD45+, CD11b+, Ly6Clo, Ly6G+) and therefore less inhibition of T-cell activity is observed. Fyn increases tumor growth due to MDSC migration induction, their augmented expression of ARG1 and CD80, as well as their enhanced functional immunosuppressive activity (20). This work opens up new avenues for future investigations to understand glioma-immune microenvironment cross-talk and increases the potential efficacy of anti-glioma therapeutics. All these data suggest that Fyn inhibition in tumor cells is a novel therapeutic target for glioma treatment. Inhibiting Fyn's pro-tumoral activity has the combined effects of reducing tumor cell proliferation and migration, as well as inducing the antitumor immune response.

The incapacity of different therapeutic agents to cross the blood-brain barrier and the non-specificity of the available Fyn pharmacological inhibitors challenge the possibilities of its use as a target for glioma treatment (265). To investigate the translational implications of targeting Fyn in glioma, we propose the use of glioma pre-clinical models to test the 
efficacy of nanoparticles loaded with small interfering RNA (siRNA) against Fyn. This strategy has the advantage of being systemically administrated, since nanoparticles have the ability to cross the brain-barrier and deliver their cargo directly into brain tumors $(276,277)$. Furthermore, the combination of Fyn inhibition within glioma cells and cancer immunotherapy, such as immune checkpoint blockade (PDL1 and PD1 inhibitors), IFN $\gamma$ therapy, and Ad-hCMV-TK plus Ad-hCMV-Flt3L immune-stimulatory gene therapy $(8,12,278)$, are promising avenues to improve the efficacy of anti-glioma immunotherapies and explore novel personalized treatment for glioma patients.

\section{Nanoparticles as a Novel Anti-Glioma Therapy to Stimulate the Immune System}

Nanotechnology is a potentially promising strategy to utilize against gliomas. It offers advantages such as (1) targeted delivery of materials to specific organs and tissues; (2) antigen and adjuvant co-delivery to antigen-presenting cells (APCs); and (3) non-invasive delivery of therapeutics; while (4) providing safe and biocompatible platforms for combinational immunotherapy, especially with immune checkpoint blockade (ICB) (279). In particular, Kuai, et al. have developed a synthetic high-density lipoprotein ( $\mathrm{HHDL}$ ) nanodisc platform composed of phospholipids and apolipoprotein A1-mimetic peptides (280). As a platform for cancer immunotherapy, sHDL has ideal properties, including multiple cargo loading sites for antigens, adjuvants, and chemotherapeutics, and its small size $(10 \mathrm{~nm})$ mediates efficient delivery of cargo to draining lymph nodes or directly to tumors for cytotoxic effects. In this regard, we have demonstrated strong anti-tumor efficacy of sHDL delivering GBM neoantigens or a chemotherapeutic agent docetaxel (DTX) in murine models of glioma $(21,22)$.

The sHDL nanodiscs using GBM neoantigens were synthesized by modifying neoantigen peptides with a reduction-sensitive cysteine-serine-serine linker, which was reacted with a dioleoyl$s n$-glycero-3-phosphoethanolamine- $N$-[3-(2-pyridyldithio) propionate] (PDP)-modified lipid to produce neoantigen-lipid conjugates $(22,280)$. Loading of neoantigen-lipid conjugates and CpG (a Toll-like receptor-9 agonist) in sHDL was mediated via hydrophobic interactions after simple mixing. Nanodiscs were taken up by DCs, leading to strong localization with endosomes/ lysosomes, sustained epitope-MHC I presentation, and crosspriming of CD8+ T cells against GBM. Mice were inoculated with an orthotopic GL261 model and treated with a combination of nanodiscs carrying three GBM neoantigens and anti-PD-L1. The results showed up to 100 -fold higher IFN $\gamma+\mathrm{T}$ cell responses and eradicated $30 \%$ of gliomas, compared with soluble vaccine + antiPD-L1 treatment (22). Furthermore, there were no signs of recurrence through day 90 , on which mice were re-challenged in the contralateral hemisphere and did not show any signs of neurological deficit as well (22). These results are particularly exciting as they demonstrate immunological memory and the ability of glioma-specific $\mathrm{T}$ cells to traverse the blood brain barrier (BBB) and exert cytotoxic effects against gliomas.

Nanodiscs carrying DTX and CpG were synthesized similarly (21). One of the main barriers of effective glioma treatment is the
$\mathrm{BBB}$, which provides a physical resistance to $\mathrm{GBM}$ chemotherapeutic treatment. By loading sHDL nanodiscs with DTX and CpG and injecting them intrathecally, the BBB was bypassed, allowing the nanodiscs to diffuse through the entire tumor $(21,281)$. When sHDL-DTX-CpG was administered to orthotopic GL26 tumor-bearing mice, a 2-fold increase in survival was observed, compared with DTX, DTX-CpG, or DTXsHDL treatment (21). sHDL-DTX-CpG triggered immunogenic cell death, as evidenced by high expression of "eat me" and "danger" signals, such as calreticulin and HMGB1 on the surface of tumor cells. sHDL-DTX-CpG also promoted recruitment of APCs as well as CD8+ T cells into GBM tumors (21). As standard therapy for GBM is normally a combination of radiation therapy and chemotherapy, GBM-bearing mice were treated with a combination of sHDL-DTX-CpG and radiation therapy, which resulted in $80 \%$ tumor regression and no tumor recurrence post tumor re-challenge (21). Exemplified by these two examples using the sHDL nanodisc platform, nanotechnology is a novel and effective therapy to stimulate a comprehensive anti-GBM immune response.

\section{Current Therapies Aimed at Targeting Epigenetic Pathways in Glioma and Its Impact on the Immune Response}

Insights into the molecular landscape of diffuse gliomas have revealed characteristic genetic and epigenetic profiles which stratified the glioma classification $(38,47)$. Genetic anomalies associated with gliomagenesis commonly coincide with specific epigenetic mutations (282). These include but are not limited to a mutation in histone $\mathrm{H} 3$ genes such as $\mathrm{H} 3 \mathrm{~K} 27 \mathrm{M}$, and $\mathrm{H} 3 \mathrm{G} 34 \mathrm{R} / \mathrm{V}$ as well as a mutation in the epigenetic modulator gene isocitrate dehydrogenase (IDH) $(38,47)$. Owing to the reversibility of epigenetic modifications, the proteins and genes that regulate these changes have become new targets in the treatment of glioma (282). Epigenetic mechanisms are critical for many processes in cancer-immunity cycle. Also, epigenetic pathways can impact both tumor cells as well as immune cells resulting in a negative impact on the anti-tumor immune response. For instance, DNA methylation-associated mutagenesis is the single most important source of genetic alterations, leading to neoantigen formation in most cancers including glioma $(283,284)$.

Several therapies aimed at targeting epigenetic pathways are being examined for their anti-glioma abilities. Several of these therapies target proteins that mediate histone modifications. Examples of these therapies include EZH2 inhibitors, DNA methyltransferase (DNMT) inhibitors, histone deacetylase (HDAC) inhibitors, mutant IDH inhibitors, and BET inhibitors (285). The enhancer of zeste homolog 1/2 (EZH1/2) is the main subunit of PRC2 responsible for the trimethylation of Histone $\mathrm{H} 3$ lysine 27 (H3K27me3), which controls stem cell and oncogenic gene expression programs (282). The H3K27 mutation has been shown to inhibit polycomb repressor complex 2 (PRC2) activity which leads to hypomethylation of $\mathrm{H} 3 \mathrm{~K} 27$ and expression of potential oncogenes (282). EZH2 overexpression is associated with poor GBM prognosis, and reducing levels of EZH2 expression in vivo resulted in a reduced tumor progression, which suggests the efficacy 
of EZH2 inhibitors as anti-glioma therapies (286, 287). EZH2 inhibitor, Tazemetostat, alone, and in conjunction with other therapies, is currently in clinical trials for treating pediatric glioma with EZH2, SMARCB1, or SMARCA4 mutations (ClinicalTrials.gov IDs NCT03213665, NCT03155620). These mutations affect gene expression via the regulation of chromatin remodeling.

DNA methylation is the most commonly studied epigenetic modification in cancer (285), and methylation signatures are included in glioma classification (288). Gliomas harboring mutant IDH1 display high levels of DNA hypermethylation in CpG rich domains, which are associated with increased tumor progression and altered gene expression $(289,290)$. Inhibitors of mutated IDH1/ 2 enzymes entered clinical trials and represent a novel drug class for targeted therapy of gliomas. These include AG-881, AG-120, and AG-221, all of which are being tested in preclinical and clinical settings. Preliminary results from Phase I clinical trials with IDH inhibitors demonstrated an objective response rate ranging from $31 \%$ to $40 \%$ with durable responses (>1 year) (291). To date, AG120 showed the most clinically promising results as an orally administered, reversible, and highly selective small-molecule inhibitor of mutant IDH1/R132H cancers $(292,293)$.

Another group of drugs targeting the glioma methylation status are DNMT inhibitors, which are now being studied as potential anti-mIDH1 glioma therapies. DNMTs promote cancer generation by causing hypermethylation of tumor suppressor gene enhancers and promoter regions $(18,285)$. Early studies have shown antiglioma efficacy of DNMT inhibitors in vivo and in vitro $(294,295)$. Despite the preclinical successes, a representative DNMT inhibitor, 5-aza-2'-deoxycytidine, has been shown to have minimal efficacy in early clinical trials (290). Recent studies showed a strong connection between epigenetics and cytokine production in tumor cells. One example is DNMT inhibition which can trick cancer cells into behaving as virus-infected cells, leading to activation of the interferon pathway $(296,297)$. In glioma, IL-6 promotes hypermethylation of the Sp1-binding site in the miR142-3p gene promoter, preventing binding of Sp1 and inhibiting miR-142-3p expression (298). These changes were shown to enhance the effectiveness of immune checkpoint inhibitors (296, 297). Moreover, multiple studies have shown that the PD-L1 level can be regulated by epigenetic mechanisms. For example, in IDH1 mutated glioma, we have shown that methylation in PD-L1 promoter negatively correlates with $\mathrm{PD}-\mathrm{L} 1$ expression and prognosis (24).

Histone acetylation plays a role in gene expression. Whilst acetylation is generally associated with elevated transcription, deacetylated histones are generally associated with repressed genes (299). HDAC enzymes are differentially expressed in glioma and have been shown to play a role in glioma progression $(18,299)$. Several pre-clinical studies have shown an effective response for HDAC inhibitors via multiple mechanisms, including induction of tumor cell death, as well as increase radio-sensitivity, differentiation, and/or cell cycle arrest (300-302). Due to the promising results obtained from these studies, both Vorinostat and valproic acid, are currently being tested in clinical trials on gliomas as monotherapies and combinational therapies $(18,303-305)$. So far, results showed that HDAC inhibitor monotherapies are not sufficient as antiglioma therapies, but they show promise in increasing the antiglioma effects in combinational therapies (306).

Bromodomain and extra-terminal domain (BET) proteins are epigenetic chromatin readers that bind to acetyl marks of lysine residues to regulate gene expression $(282,285,307)$. BET proteins were found to be associated with high expression of oncogenes (285, 307). BET inhibitors have been identified as possible therapies for GBM patients, as they have been found to inhibit GBM cell proliferation both in vivo and in vitro by hindering cell cycle progression and reducing oncogene expression $(307,308)$. Despite the promising preclinical findings, there are no clinical trials on BET inhibitors as a treatment for glioma patients.

Multiple therapeutics targeting epigenetic pathways (epidrugs) have been approved for cancer treatment which can affect the immune response. These were approved to treat hematopoietic malignancies such as T-cell lymphoma, multiple myeloma, and myelodysplastic syndromes $(309,310)$. Even though there is no clinical application of epidrugs targeting glioma, azemetostat, a KMT6A (EZH2) inhibitor, was approved for the treatment of epithelioid sarcoma, making it the first approved histone 'writer' inhibitor and the first epidrug to treat solid tumors (311). This demonstrates promising avenues of epidrugs to target solid tumors that have pronounced epigenetic dysregulation including glioma, which could in turn, enhance the immune response against these tumors.

\section{Inhibition of the Oncometabolite (R)-2-HG to Enhance Anti-Glioma Immunity}

Mutation in the metabolic enzyme isocitrate dehydrogenase 1 (mIDH1) at active site residue $\mathrm{R} 132 \mathrm{H}$ occur in $\sim 20-25 \%$ of infiltrative gliomas $(40,312,313)$. The mutation leads to gain-offunction catalytic activity that converts $\alpha$-ketoglutarate $(\alpha K G)$ to the onco-metabolite (R)-2-hydroxyglutarate ((R)-2-HG) (40, 314, 315). (R)-2-HG competitively inhibits histone demethylating enzymes ten-eleven translocation methylcytosine dioxygenases (TETs) and lysine-specific demethylases (KDMs) (289, 316). Inhibiting demethylation increases DNA and histone methylation, altering the epigenome, resulting in changes in the tumor transcriptome $(289,316)$. Although studies have shown that small molecule inhibitors targeting IDH1-R132H have been effective in impairing tumor progression as monotherapy in pre-clinical models (317), in phase I clinical trials they have not been effective as monotherapies (NCT02381886). We have previously shown that $\mathrm{mIDH}-\mathrm{R} 132 \mathrm{H}$, in the context of ATRX and TP53 inactivation, epigenetically reprograms gene regions corresponding to DNA repair proteins in human and murine glioma cell cultures (44). Treatment with AGI-5918, a small molecule inhibitor prior to radiotherapy, downregulated DNA repair gene expression, thus making the tumor cells radiosensitive. These results highlight the need for a combinatorial treatment strategy to effectively impede $\mathrm{mIDH} 1$ progression.

The onco-metabolite (R)-2-HG has been shown to repress expression of key immune regulatory genes, such as CCL2, CXCL-2 and C5-a, which are primarily involved in mediating lymphocytes' trafficking to the mIDH1 glioma TME (94). 
Recently, one study demonstrated that combination of PD-1 inhibition and the mIDH1 inhibitor BAY1436032 extended the survival of mice implanted with GL261-IDH1R132H glioma cells by overriding the immune suppressive environment mediated by (R)-2-HG (318).

We recently demonstrated that in genetically engineered $\mathrm{mIDH} 1$ mouse gliomas, resembling human mutant IDH1 astrocytoma, (R)2-HG inhibition in combination with SOC increased the infiltration of DCs and anti-tumor specific T cells in the TME, while decreasing the infiltration of immunosuppressive MDSCs, Tregs, and M2 macrophages compared to saline treated mice (24). We also observed that $\mathrm{mIDH} 1$ glioma cells exhibit lower levels of PD-L1 expression (24). In response to (R)-2-HG inhibition, PD-L1 expression levels on $\mathrm{mIDH} 1$ glioma cells significantly increased to those observed in wild type IDH gliomas (24). Numerous preclinical solid tumor models have demonstrated that the immune checkpoint blockade of PD-1/PD-L1 interaction prevents T cell exhaustion, resulting in enhanced anti-tumor immune activity and improved MS (9, 319, 320). We previously demonstrated that PD-L1 checkpoint blockade as monotherapy elicited a small increase in MS in mice bearing syngeneic glioma, with only a few long-term survivors (9). However, immune-checkpoint blockade used as monotherapy has failed in Phase III clinical trials to improve OS of patients with glioma (12). We observed that IDH1-R132H inhibition used in combination with SOC and anti-PD-L1 immune checkpoint blockade increased the frequency of tumorspecific cytotoxic CD8+ T cells and IFN- $\gamma$ release within the TME (24). Strikingly, long-term survivors from IDH1-R132H inhibition in combination with SOC and anti-PD-L1 immune checkpoint treatment group remained tumor-free post $\mathrm{mIDH} 1$ glioma rechallenging in the contralateral hemisphere, indicating the development of anti-mIDH1 glioma immunological memory (24). This is a critical factor in determining the success of immunetherapeutic approaches in gliomas. A robust anti-tumor $\mathrm{T}$ cell response and the presence of anti-glioma immunological memory are required to eradicate any remnant tumor cells post-surgery and prevent recurrence.

Collectively, upon metabolic reprogramming it is possible to achieve anti-mIDH1 glioma immunity. The precise elucidation of the immune pathways affected by (R)-2-HG will lead to an understanding of the underlying biological processes and will provide better therapeutic approaches for $\mathrm{mIDH} 1$ glioma patients.

\section{FUTURE PROSPECTS AND CONCLUSIONS}

The path for immunotherapies against glioma has started more than a decade ago and the lack of sustained clinical beneficial outcomes demonstrates the challenge that this tumor represents $(12,17,79,84,249)$. Malignant gliomas are tumors intrinsically difficult to target by immunotherapies due to their heterogeneity, their immunosuppressive TME and the particular cross-talk of the CNS and the immune system $(6,11)$. However, as tumor recurrence occurs almost always in glioma patients, since these tumors are virtually impossible to completely resect due to their infiltrative nature, anti-glioma immunological memory would be highly beneficial desirable for these patients. Also, because the immunosuppressive TME is related to glioma aggressiveness, trying to counteract this milieu represents an appealing idea for oncologists and researchers.

Research in immunotherapies against glioma developed in parallel with the broadening of our understanding regarding the molecular landscape associated to different types of glioma. These studies demonstrated that entities before defined under the same WHO group, were not as homogeneous as they were thought to be $(38,40,321)$. The genetic and epigenetic data gathered so far enabled the classification of gliomas in terms of their intrinsic characteristics, in combination with the histological features, and unveiled how complex these tumors are. Also, with the advent of state-of-the-art technologies, such as scRNA-Seq, it was realized not only that gliomas have intratumor heterogeneity, but also, that this state could fluctuate, for example, depending on the stage of the treatment at which the biopsy is taken. Ideally, in the future, the advancements in both, sequencing methodologies and immunotherapeutic strategies, will be combined to design and apply more targeted therapies for glioma patients (Figure 2).

This overwhelming amount of information allowed the development of more sophisticated murine models for the preclinical testing of immune-mediated therapies for glioma. Mouse models that recapitulate the human disease, with animals harboring brain tumors encoding for the specific genetic and epigenetic alterations described, have been generated with techniques, such as the Sleeping Beauty method, that enable the concomitant study of the surrounding immune response.

Even though these advancements represented a milestone in the exploration of immunotherapies against glioma, the translation of pre-clinical findings to the clinical setting has not yielded consistent or sustained beneficial outcomes for patients. This drawback reveals that animal models need to be further adjusted to the genetics/ biology of these tumors and that we should be cautious about generalizing the potential clinical response for a particular immunemediated therapy. So far, the data gathered from clinical trials and the information obtained in pre-clinical models have been useful in demonstrating that the molecular features of glioma influence the anti-tumor immune response and the clinical consequences of the administration of an immunotherapy.

Despite the lack of a substantial benefit for glioma patients treated with immunotherapies, the medical-research community has learnt important lessons from these pitfalls. Currently, we know that the immune-mediated approach to treat glioma should be combinational, not only by considering more than one TAA or TSA to target, but also by integrating different immunotherapeutic strategies. For example, DC vaccines could be combined with ICI and OV therapy, to enhance the development of adaptive anti-tumor immunity. The possibility of combinational therapies is encouraging, as we have been capable of developing different immune-mediated strategies against this tumor. However, it rises the complexity of tumor treatment, as the number of combinations for drug doses, times and routes for drug administration increases exponentially. 


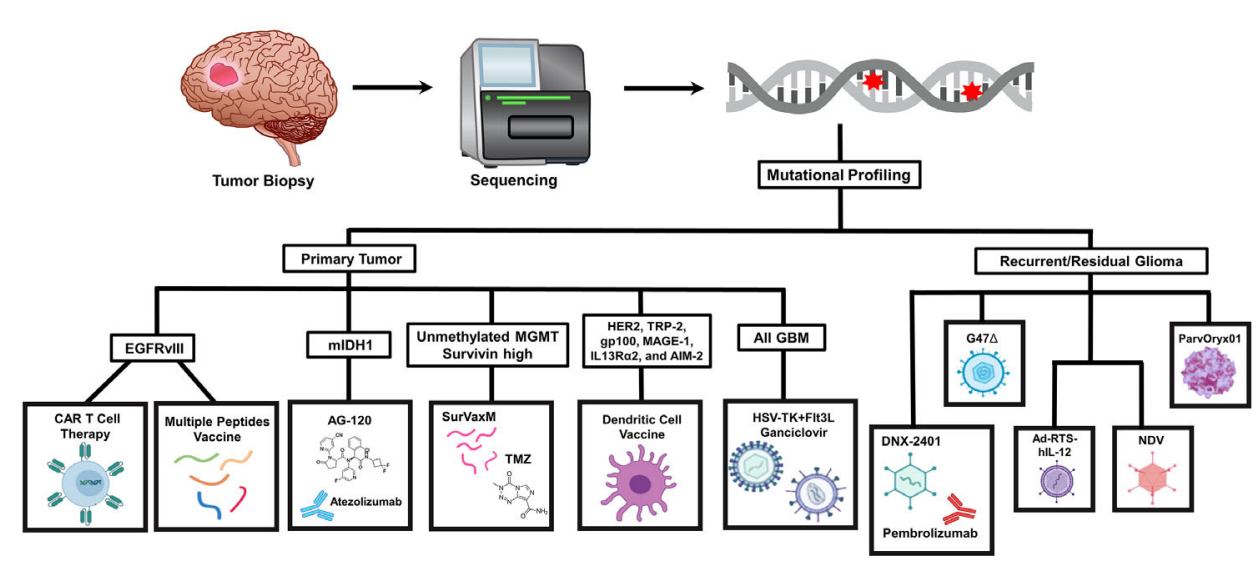

FIGURE 2 | Genomic sequencing of glioma patient tumor biopsies could guide the immunotherapy strategies selected based on the mutational profile and clinical status. Tumor biopsies obtained by surgical resection undergo high-throughput genomic sequencing to identify mutations present within the cancer cells. The genetic lesions detected could be used as a decision factor to select which immunotherapy to choose. Patients with primary tumors that express specific tumor antigens can undergo a variety of immune-based treatments that address these driver mutations directly and could be combined with chemotherapeutic agents and other approaches, such as immune checkpoint inhibitors. Patients that present with recurrent or residual glioma could also be treated with gene therapy or virotherapy-mediated approaches that directly target the glioma cells to trigger immune-stimulatory mechanisms.

The great advancements in the immune-mediated approaches for glioma therapy and the development of BBB penetrating and tumortargeted ways of drug administration in the pre-clinical setting has demonstrated that the research community is capable of designing new alternatives to overcome the challenges that this type of tumor presents. We believe that the key for the success of immunotherapies against glioma resides in the deep understanding of the biology of this tumor and in the precise combination of diverse therapeutic approaches. It is important to carefully revise the clinical trial results and to compare them with the pre-clinical data, in order to learn from the failures and generate better animal models.

We hope that the data discussed in this review highlight the importance of taking into account the molecular features of gliomas when considering immunotherapies and that it will shed light on the aspects that we still need to tackle to successfully harness the immune system against these tumors.

\section{AUTHOR CONTRIBUTIONS}

All the authors contributed to the writing of the manuscript. MC, AS, and NG prepared Figure 1 and tables. SC prepared Figure 2.

\section{REFERENCES}

1. Ostrom QT, Gittleman H, Fulop J, Liu M, Blanda R, Kromer C, et al. CBTRUS Statistical Report: Primary Brain and Central Nervous System Tumors Diagnosed in the United States in 2008-2012. Neuro-Oncology (2015) 17(Suppl 4):iv1-62. doi: 10.1093/neuonc/nov189

2. Molinaro AM, Taylor JW, Wiencke JK, Wrensch MR. Genetic and Molecular Epidemiology of Adult Diffuse Glioma. Nat Rev Neurol (2019) 15(7):405-17. doi: 10.1038/s41582-019-0220-2

3. Mrugala MM. Advances and Challenges in the Treatment of Glioblastoma: A Clinician's Perspective. Discovery Med (2013) 15(83):221-30.
All authors contributed to the article and approved the submitted version.

\section{FUNDING}

This work was supported by NIH/NINDS Grants, R37-NS094804, R01-NS105556 and 1R21NS107894 to MGC; NIH/NINDS Grants R01-NS076991, and R01-NS096756 to P.R.L.; NIH/NIBIB: R01EB022563 grant to MGC, PL and JJM; the Department of Neurosurgery, the Rogel Cancer Center, Program in Cancer Hematopoiesis and Immunology (CHI), the ChadTough Foundation, Pediatric Brain Tumor Foundation, and Leah's Happy Hearts to MGC. and PL; RNA Biomedicine Grant F046166, Forbes Foundation Grant, University of Michigan Medical School, Rogel Cancer Center Scholar, University of Michigan Medical School to M.G.C.; T32 CA009676-26 Cancer Biology Training Grant to MAl; UL1 TR002240 for the Michigan Institute for Clinical and Health Research (MICHR), Postdoctoral Translational Scholars Program (PTSP), Project F049768 to AC and American Brain Tumor Association Basic Research Fellowship "in Memory of Bruce and Brian Jackson" to MG-F.

4. Parrish K, Sarkaria JN, Elmquist WF. Improving Drug Delivery to Primary and Metastatic Brain Tumors: Strategies to Overcome the Blood-Brain Barrier. Clin Pharmacol Ther (2015) 97(4):336-46. doi: $10.1002 /$ cpt.71

5. Mallick S, Benson R, Hakim A, Rath GK. Management of Glioblastoma After Recurrence: A Changing Paradigm. J Egyptian Natl Cancer Institute (2016) 28(4):199-210. doi: 10.1016/j.jnci.2016.07.001

6. Quail DF, Joyce JA. The Microenvironmental Landscape of Brain Tumors. Cancer Cell (2017) 31(3):326-41. doi: 10.1016/j.ccell.2017.02.009

7. Antunes ARP, Scheyltjens I, Duerinck J, Neyns B, Movahedi K, Van Ginderachter JA. Understanding the Glioblastoma Immune 
Microenvironment as Basis for the Development of New Immunotherapeutic Strategies. Elife (2020) 9:e52176. doi: 10.7554/eLife.52176

8. Kamran N, Alghamri MS, Nunez FJ, Shah D, Asad AS, Candolfi M, et al. Current State and Future Prospects of Immunotherapy for Glioma. Immunotherapy (2018) 10(4):317-39. doi: 10.2217/imt-2017-0122

9. Kamran N, Kadiyala P, Saxena M, Candolfi M, Li Y, Moreno-Ayala MA, et al. Immunosuppressive Myeloid Cells' Blockade in the Glioma Microenvironment Enhances the Efficacy of Immune-Stimulatory Gene Therapy. Mol Ther (2017) 25(1):232-48. doi: 10.1016/j.ymthe.2016.10.003

10. Razavi S-M, Lee KE, Jin BE, Aujla PS, Gholamin S, Li G. Immune Evasion Strategies of Glioblastoma. Front Surg (2016) 3:11. doi: 10.3389/ fsurg.2016.00011

11. Kamran N, Chandran M, Lowenstein PR, Castro MG. Immature Myeloid Cells in the Tumor Microenvironment: Implications for Immunotherapy. Clin Immunol (2018) 189:34-42. doi: 10.1016/j.clim.2016.10.008

12. Garcia-Fabiani MB, Ventosa M, Comba A, Candolfi M, Nicola Candia AJ, Alghamri MS, et al. Immunotherapy for Gliomas: Shedding Light on Progress in Preclinical and Clinical Development. Expert Opin Investig Drugs (2020) 29(7):659-84. doi: 10.1080/13543784.2020.1768528

13. Gieryng A, Pszczolkowska D, Walentynowicz KA, Rajan WD, Kaminska B. Immune Microenvironment of Gliomas. Lab Invest (2017) 97(5):498-518. doi: 10.1038/labinvest.2017.19

14. Lu J, Li H, Chen Z, Fan L, Feng S, Cai X, et al. Identification of 3 Subpopulations of Tumor-Infiltrating Immune Cells for Malignant Transformation of Low-Grade Glioma. Cancer Cell Int (2019) 19(1):1-13. doi: 10.1186/s12935-019-0972-1

15. Alghamri MS, Avvari RP, Thalla R, Kamran N, Zhang L, Ventosa M, et al. GCSF Secreted by Epigenetically Reprogrammed Mutant IDH1 Glioma Stem Cells Reverses the Myeloid Cells'-Mediated Immunosuppressive Tumor Microenvironment. bioRxiv (2020) 2020.07.22.215954. doi: 10.1101/ 2020.07.22.215954

16. Stylli SS, Luwor RB, Ware TM, Tan F, Kaye AH. Mouse Models of Glioma. J Clin Neurosci (2015) 22(4):619-26. doi: 10.1016/j.jocn.2014.10.013

17. Calinescu A-A, Kamran N, Baker G, Mineharu Y, Lowenstein PR, Castro MG. Overview of Current Immunotherapeutic Strategies for Glioma. Immunotherapy (2015) 7(10):1073-104. doi: 10.2217/imt.15.75

18. Zang L, Kondengaden SM, Che F, Wang L, Heng X. Potential EpigeneticBased Therapeutic Targets for Glioma. Front Mol Neurosci (2018) 11:408. doi: 10.3389/fnmol.2018.00408

19. Reddy RG, Bhat UA, Chakravarty S, Kumar A. Advances in Histone Deacetylase Inhibitors in Targeting Glioblastoma Stem Cells. Cancer Chemotherapy Pharmacol (2020) 86(2):165-79. doi: 10.1007/s00280-020-04109-w

20. Comba A, Dunn PJ, Argento AE, Kadiyala P, Ventosa M, Patel P, et al. Fyn Tyrosine Kinase, a Downstream Target of Receptor Tyrosine Kinases, Modulates Antiglioma Immune Responses. Neuro-Oncology (2020) 22 (6):806-18. doi: 10.1093/neuonc/noaa006

21. Kadiyala P, Li D, Nuñez FM, Altshuler D, Doherty R, Kuai R, et al. HighDensity Lipoprotein-Mimicking Nanodiscs for Chemo-Immunotherapy Against Glioblastoma Multiforme. ACS Nano (2019) 13(2):1365-84. doi: 10.1021/acsnano.8b06842

22. Scheetz L, Kadiyala P, Sun X, Son S, Hassani Najafabadi A, Aikins M, et al. Synthetic High-Density Lipoprotein Nanodiscs for Personalized Immunotherapy Against Gliomas. Clin Cancer Res (2020) 26(16):4369-80. doi: 10.1158/1078-0432.CCR-20-0341

23. Friedrich M, Bunse L, Wick W, Platten M. Perspectives of Immunotherapy in Isocitrate Dehydrogenase-Mutant Gliomas. Curr Opin Oncol (2018) 30 (6):368-74. doi: 10.1097/CCO.0000000000000478

24. Kadiyala PCS, Gauss J, Garcia-Fabiani M, Núñez FJ, Nunez F, Alghamri MS, et al. Castro M Inhibition of 2-Hydroxyglutrate Elicits MetabolicReprograming and Mutant IDH1 Glioma Immunity. J Clin Invest (2020) 131(4):e139542. doi: 10.1101/2020.05.11.086371

25. Zong H, Parada LF, Baker SJ. Cell of Origin for Malignant Gliomas and its Implication in Therapeutic Development. Cold Spring Harb Perspect Biol (2015) 7(5):a020610. doi: 10.1101/cshperspect.a020610

26. Ostrom QT, Gittleman H, Truitt G, Boscia A, Kruchko C, Barnholtz-Sloan JS. CBTRUS Statistical Report: Primary Brain and Other Central Nervous System Tumors Diagnosed in the United States in 2011-2015. Neuro Oncol (2018) 20(suppl_4):iv1-86. doi: 10.1093/neuonc/noy131
27. Louis DN, Ohgaki H, Wiestler OD, Cavenee WK, Burger PC, Jouvet A, et al. The 2007 WHO Classification of Tumours of the Central Nervous System. Acta Neuropathol (2007) 114(2):97-109. doi: 10.1007/s00401-007-0243-4

28. Louis DN, Perry A, Reifenberger G, Von Deimling A, Figarella-Branger D, Cavenee WK, et al. The 2016 World Health Organization Classification of Tumors of the Central Nervous System: A Summary. Acta Neuropathol (2016) 131(6):803-20. doi: 10.1007/s00401-016-1545-1

29. Osswald M, Jung E, Sahm F, Solecki G, Venkataramani V, Blaes J, et al. Brain Tumour Cells Interconnect to a Functional and Resistant Network. Nature (2015) 528(7580):93-8. doi: 10.1038/nature16071

30. Perry A, Wesseling P. Histologic Classification of Gliomas. Handb Clin Neurol (2016) 134:71-95. doi: 10.1016/B978-0-12-802997-8.00005-0

31. Reifenberger G, Wirsching HG, Knobbe-Thomsen CB, Weller M. Advances in the Molecular Genetics of Gliomas - Implications for Classification and Therapy. Nat Rev Clin Oncol (2017) 14(7):434-52. doi: 10.1038/ nrclinonc.2016.204

32. Masui K, Mischel PS, Reifenberger G. Molecular Classification of Gliomas. Handb Clin Neurol (2016) 134:97-120. doi: 10.1016/B978-0-12-8029978.00006-2

33. Parsons DW, Jones S, Zhang X, Lin JC, Leary RJ, Angenendt P, et al. An Integrated Genomic Analysis of Human Glioblastoma Multiforme. Science (2008) 321(5897):1807-12. doi: 10.1126/science.1164382

34. Brennan CW, Verhaak RG, McKenna A, Campos B, Noushmehr H, Salama SR, et al. The Somatic Genomic Landscape of Glioblastoma. Cell (2013) 155 (2):462-77. doi: 10.1016/j.cell.2013.09.034

35. Ludwig K, Kornblum HI. Molecular Markers in Glioma. J Neuro-Oncol (2017) 134(3):505-12. doi: 10.1007/s11060-017-2379-y

36. Masui K, Mischel PS, Reifenberger G. Molecular Classification of Gliomas. In: Handbook of Clinical Neurology, vol. 134. The Netherlands: Elsevier (2016). p. 97-120.

37. Wesseling P, Capper D. WHO 2016 Classification of Gliomas. Neuropathol Appl Neurobiol (2018) 44(2):139-50. doi: 10.1111/nan.12432

38. Sturm D, Witt H, Hovestadt V, Khuong-Quang DA, Jones DT, Konermann C, et al. Hotspot Mutations in H3F3A and IDH1 Define Distinct Epigenetic and Biological Subgroups of Glioblastoma. Cancer Cell (2012) 22(4):425-37. doi: 10.1016/j.ccr.2012.08.024

39. Cancer Genome Atlas Research N, Brat DJ, Verhaak RG, Aldape KD, Yung WK, Salama SR, et al. Comprehensive, Integrative Genomic Analysis of Diffuse Lower-Grade Gliomas. N Engl J Med (2015) 372(26):2481-98. doi: 10.1056/NEJMoa1402121

40. Ceccarelli M, Barthel FP, Malta TM, Sabedot TS, Salama SR, Murray BA, et al. Molecular Profiling Reveals Biologically Discrete Subsets and Pathways of Progression in Diffuse Glioma. Cell (2016) 164(3):550-63. doi: 10.1016/ j.cell.2015.12.028

41. Bai H, Harmanci AS, Erson-Omay EZ, Li J, Coskun S, Simon M, et al. Integrated Genomic Characterization of IDH1-Mutant Glioma Malignant Progression. Nat Genet (2016) 48(1):59-66. doi: 10.1038/ng.3457

42. Cancer Genome Atlas Research N. Comprehensive Genomic Characterization Defines Human Glioblastoma Genes and Core Pathways. Nature (2008) 455(7216):1061-8. doi: 10.1038/nature07385

43. Dang L, White DW, Gross S, Bennett BD, Bittinger MA, Driggers EM, et al. Cancer-Associated IDH1 Mutations Produce 2-Hydroxyglutarate. Nature (2009) 462(7274):739-44. doi: 10.1038/nature08617

44. Núñez FJ, Mendez FM, Kadiyala P, Alghamri MS, Savelieff MG, GarciaFabiani MB, et al. IDH1-R132H Acts as a Tumor Suppressor in Glioma Via Epigenetic Up-Regulation of the DNA Damage Response. Sci Trans Med (2019) 11(479):eaaq1427. doi: 10.1126/scitranslmed.aaq1427

45. Yan H, Parsons DW, Jin G, McLendon R, Rasheed BA, Yuan W, et al. IDH1 and IDH2 Mutations in Gliomas. New Engl J Med (2009) 360(8):765-73. doi: 10.1056/NEJMoa0808710

46. Noushmehr H, Weisenberger DJ, Diefes K, Phillips HS, Pujara K, Berman BP, et al. Identification of a Cpg Island Methylator Phenotype That Defines a Distinct Subgroup of Glioma. Cancer Cell (2010) 17(5):510-22. doi: 10.1016/ S1040-1741(10)79529-4

47. Wiestler B, Capper D, Sill M, Jones DT, Hovestadt V, Sturm D, et al. Integrated DNA Methylation and Copy-Number Profiling Identify Three Clinically and Biologically Relevant Groups of Anaplastic Glioma. Acta Neuropathol (2014) 128(4):561-71. doi: 10.1007/s00401-014-1315-x 
48. Zhang YH, Li Z, Zeng T, Pan X, Chen L, Liu D, et al. Distinguishing Glioblastoma Subtypes by Methylation Signatures. Front Genet (2020) 11:604336. doi: 10.3389/fgene.2020.604336

49. Capper D, Jones DTW, Sill M, Hovestadt V, Schrimpf D, Sturm D, et al. DNA Methylation-Based Classification of Central Nervous System Tumours. Nature (2018) 555(7697):469-74. doi: 10.1038/nature26000

50. Wick W, Weller M, van den Bent M, Sanson M, Weiler M, von Deimling A, et al. MGMT Testing-the Challenges for Biomarker-Based Glioma Treatment. Nat Rev Neurol (2014) 10(7):372-85. doi: 10.1038/nrneurol.2014.100

51. Jones T, Holland E. Standard of Care Therapy for Malignant Glioma and its Effect on Tumor and Stromal Cells. Oncogene (2012) 31(16):1995-2006. doi: 10.1038/onc.2011.398

52. Jones C, Perryman L, Hargrave D. Paediatric and Adult Malignant Glioma: Close Relatives or Distant Cousins? Nat Rev Clin Oncol (2012) 9(7):400-13. doi: 10.1038/nrclinonc.2012.87

53. Mackay A, Burford A, Carvalho D, Izquierdo E, Fazal-Salom J, Taylor KR, et al. Integrated Molecular Meta-Analysis of 1,000 Pediatric High-Grade and Diffuse Intrinsic Pontine Glioma. Cancer Cell (2017) 32(4):520-37.e5. doi: 10.1016/j.ccell.2017.08.017

54. Braunstein S, Raleigh D, Bindra R, Mueller S, Haas-Kogan D. Pediatric High-Grade Glioma: Current Molecular Landscape and Therapeutic Approaches. J Neuro-Oncol (2017) 134(3):541-9. doi: 10.1007/s11060-0172393-0

55. Jones C, Karajannis MA, Jones DTW, Kieran MW, Monje M, Baker SJ, et al. Pediatric High-Grade Glioma: Biologically and Clinically in Need of New Thinking. Neuro-oncology (2017) 19(2):153-61. doi: 10.1093/neuonc/ now101

56. Schwartzentruber J, Korshunov A, Liu XY, Jones DT, Pfaff E, Jacob K, et al. Driver Mutations in Histone H3.3 and Chromatin Remodelling Genes in Paediatric Glioblastoma. Nature (2012) 482(7384):226-31. doi: 10.1038/ nature 10833

57. Wu G, Broniscer A, McEachron TA, Lu C, Paugh BS, Becksfort J, et al. Somatic Histone H3 Alterations in Pediatric Diffuse Intrinsic Pontine Gliomas and non-Brainstem Glioblastomas. Nat Genet (2012) 44(3):2513. doi: $10.1038 /$ ng. 1102

58. Vanan MI, Eisenstat DD. Management of High-Grade Gliomas in the Pediatric Patient: Past, Present, and Future. Neurooncol Pract (2014) 1 (4):145-57. doi: 10.1093/nop/npu022

59. Ostrom QT, Gittleman H, Truitt G, Boscia A, Kruchko C, Barnholtz-Sloan JS. CBTRUS Statistical Report: Primary Brain and Other Central Nervous System Tumors Diagnosed in the United States in 2011-2015. Neurooncology (2018) 20(suppl_4):iv1-iv86. doi: 10.1093/neuonc/noy131

60. Sturm D, Pfister SM, Jones DTW. Pediatric Gliomas: Current Concepts on Diagnosis, Biology, and Clinical Management. J Clin Oncol (2017) 35 (21):2370-7. doi: 10.1200/JCO.2017.73.0242

61. Blionas A, Giakoumettis D, Klonou A, Neromyliotis E, Karydakis P, Themistocleous MS. Paediatric Gliomas: Diagnosis, Molecular Biology and Management. Ann Transl Med (2018) 6(12):251. doi: 10.21037/ atm.2018.05.11

62. Coleman C, Stoller S, Grotzer M, Stucklin AG, Nazarian J, Mueller S. Pediatric Hemispheric High-Grade Glioma: Targeting the Future. Cancer Metastasis Rev (2020) 39(1):245-60. doi: 10.1007/s10555-020-09850-5

63. Kramm CM, Wagner S, Van Gool S, Schmid H, Sträter R, Gnekow A, et al. Improved Survival After Gross Total Resection of Malignant Gliomas in Pediatric Patients From the HIT-GBM Studies. Anticancer Res (2006) 26 (5B):3773-9.

64. Pollack IF, Agnihotri S, Broniscer A. Childhood Brain Tumors: Current Management, Biological Insights, and Future Directions. J Neurosurg Pediatr (2019) 23(3):261-73. doi: 10.3171/2018.10.PEDS18377

65. Clarke M, Mackay A, Ismer B, Pickles JC, Tatevossian RG, Newman S, et al. Infant High Grade Gliomas Comprise Multiple Subgroups Characterized by Novel Targetable Gene Fusions and Favorable Outcomes. Cancer Discov (2020) 10(7):942-63. doi: 10.1158/2159-8290.CD-19-1030

66. Mendez F, Kadiyala P, Nunez FJ, Carney S, Nunez FM, Gauss JC, et al. Therapeutic Efficacy of Immune Stimulatory Thymidine Kinase and FmsLike Tyrosine Kinase 3 Ligand (TK/Flt3L) Gene Therapy in a Mouse Model of High Grade Brainstem Glioma. Clin Cancer Res (2020). doi: 10.1158/ 1078-0432.CCR-19-3714
67. Garcia-Fabiani MB, Kadiyala P, Lowenstein PR, Castro MG. An Optimized Protocol for In Vivo Analysis of Tumor Cell Division in a Sleeping BeautyMediated Mouse Glioma Model. STAR Protoc (2020) 100044:100044. doi: 10.1016/j.xpro.2020.100044

68. Medawar PB. Immunity to Homologous Grafted Skin. III. The Fate of Skin Homographs Transplanted to the Brain, to Subcutaneous Tissue, and to the Anterior Chamber of the Eye. Br J Exp Pathol (1948) 29(1):58.

69. Engelhardt B, Vajkoczy P, Weller RO. The Movers and Shapers in Immune Privilege of the CNS. Nat Immunol (2017) 18(2):123. doi: 10.1038/ni.3666

70. Ransohoff RM, Engelhardt B. The Anatomical and Cellular Basis of Immune Surveillance in the Central Nervous System. Nat Rev Immunol (2012) 12 (9):623-35. doi: 10.1038/nri3265

71. Louveau A, Smirnov I, Keyes TJ, Eccles JD, Rouhani SJ, Peske JD, et al. Structural and Functional Features of Central Nervous System Lymphatic Vessels. Nature (2015) 523(7560):337-41. doi: 10.1038/nature14432

72. Negi N, Das BK. CNS: Not an Immunoprivilaged Site Anymore But a Virtual Secondary Lymphoid Organ. Int Rev Immunol (2018) 37(1):57-68. doi: 10.1080/08830185.2017.1357719

73. Ousman SS, Kubes P. Immune Surveillance in the Central Nervous System. Nat Neurosci (2012) 15(8):1096-101. doi: 10.1038/nn.3161

74. Norris GT, Kipnis J. Immune Cells and CNS Physiology: Microglia and Beyond. J Exp Med (2019) 216(1):60-70. doi: 10.1084/jem.20180199

75. Hoek RM, Ruuls SR, Murphy CA, Wright GJ, Goddard R, Zurawski SM, et al. Down-Regulation of the Macrophage Lineage Through Interaction With OX2 (CD200). Science (2000) 290(5497):1768-71. doi: 10.1126/ science.290.5497.1768

76. Mariani MM, Kielian T. Microglia in Infectious Diseases of the Central Nervous System. J Neuroimmune Pharmacol (2009) 4(4):448-61. doi: 10.1007/s11481-009-9170-6

77. Weiss T, Weller M, Roth P. Immunological Effects of Chemotherapy and Radiotherapy Against Brain Tumors. Expert Rev Anticancer Ther (2016) 16 (10):1087-94. doi: 10.1080/14737140.2016.1229600

78. Sampson JH, Gunn MD, Fecci PE, Ashley DM. Brain Immunology and Immunotherapy in Brain Tumours. Nat Rev Cancer (2019) 20(1):12-25. doi: 10.1038/s41568-019-0224-7

79. Bagley SJ, Desai AS, Nasrallah MP, O’Rourke DM. Immunotherapy and Response Assessment in Malignant Glioma: Neuro-Oncology Perspective. Topics Magn Reson Imaging (2020) 29(2):95-102. doi: 10.1097/ RMR.0000000000000233

80. Neftel C, Laffy J, Filbin MG, Hara T, Shore ME, Rahme GJ, et al. An Integrative Model of Cellular States, Plasticity, and Genetics for Glioblastoma. Cell (2019) 178(4):835-49. e21. doi: 10.1016/j.cell.2019.06.024

81. Dirkse A, Golebiewska A, Buder T, Nazarov PV, Muller A, Poovathingal S, et al. Stem Cell-Associated Heterogeneity in Glioblastoma Results From Intrinsic Tumor Plasticity Shaped by the Microenvironment. Nat Commun (2019) 10(1):1-16. doi: 10.1038/s41467-019-09853-z

82. Bernstock JD, Mooney JH, Ilyas A, Chagoya G, Estevez-Ordonez D, Ibrahim A, et al. Molecular and Cellular Intratumoral Heterogeneity in Primary Glioblastoma: Clinical and Translational Implications. J Neurosurg (2019) 1 (aop):1-9. doi: 10.3171/2019.5.JNS19364

83. Galea I, Bechmann I, Perry VH. What is Immune Privilege (Not)? Trends Immunol (2007) 28(1):12-8. doi: 10.1016/j.it.2006.11.004

84. Jackson C, Ruzevick J, Phallen J, Belcaid Z, Lim M. Challenges in Immunotherapy Presented by the Glioblastoma Multiforme Microenvironment. Clin Dev Immunol (2011) 2011:732413. doi: 10.1155/2011/732413

85. Chen Z, Feng X, Herting CJ, Garcia VA, Nie K, Pong WW, et al. Cellular and Molecular Identity of Tumor-Associated Macrophages in Glioblastoma. Cancer Res (2017) 77(9):2266-78. doi: 10.1158/0008-5472.CAN-16-2310

86. Müller S, Kohanbash G, Liu SJ, Alvarado B, Carrera D, Bhaduri A, et al. Single-Cell Profiling of Human Gliomas Reveals Macrophage Ontogeny as a Basis for Regional Differences in Macrophage Activation in the Tumor Microenvironment. Genome Biol (2017) 18(1):234. doi: 10.1186/s13059017-1362-4

87. Jurga AM, Paleczna M, Kuter KZ. Overview of General and Discriminating Markers of Differential Microglia Phenotypes. Front Cell Neurosci (2020) 14:198. doi: 10.3389/fncel.2020.00198

88. Klemm F, Maas RR, Bowman RL, Kornete M, Soukup K, Nassiri S, et al. Interrogation of the Microenvironmental Landscape in Brain Tumors 
Reveals Disease-Specific Alterations of Immune Cells. Cell (2020) 181 (7):1643-60.e17. doi: 10.1016/j.cell.2020.05.007

89. Gielen PR, Schulte BM, Kers-Rebel ED, Verrijp K, Bossman SA, Ter Laan M, et al. Elevated Levels of Polymorphonuclear Myeloid-Derived Suppressor Cells in Patients With Glioblastoma Highly Express S100A8/9 and Arginase and Suppress T Cell Function. Neuro-oncology (2016) 18(9):1253-64. doi: 10.1093/neuonc/now034

90. Alban TJ, Bayik D, Otvos B, Rabljenovic A, Leng L, Jia-Shiun L, et al. Glioblastoma Myeloid-Derived Suppressor Cell Subsets Express Differential Macrophage Migration Inhibitory Factor Receptor Profiles That can be Targeted to Reduce Immune Suppression. Front Immunol (2020) 11:1191. doi: 10.3389/fimmu.2020.01191

91. Cassetta L, Baekkevold ES, Brandau S, Bujko A, Cassatella MA, Dorhoi A, et al. Deciphering Myeloid-Derived Suppressor Cells: Isolation and Markers in Humans, Mice and non-Human Primates. Cancer Immunol Immunother (2019) 68(4):687-97. doi: 10.1007/s00262-019-02302-2

92. Deng G. Tumor-Infiltrating Regulatory T Cells: Origins and Features. Am J Clin Exp Immunol (2018) 7(5):81.

93. Huettner C, Czub S, Kerkau S, Roggendorf W, Tonn J-C. Interleukin 10 is Expressed in Human Gliomas In Vivo and Increases Glioma Cell Proliferation and Motility In Vitro. Anticancer Res (1997) 17(5A):3217-24.

94. Amankulor NM, Kim Y, Arora S, Kargl J, Szulzewsky F, Hanke M, et al. Mutant IDH1 Regulates the Tumor-Associated Immune System in Gliomas. Genes Dev (2017) 31(8):774-86. doi: 10.1101/gad.294991.116

95. Verhaak RG. Moving the Needle: Optimizing Classification for Glioma. Sci Trans Med (2016) 8(350):350fs14. doi: 10.1126/scitranslmed.aah4740

96. Verhaak RG, Hoadley KA, Purdom E, Wang V, Qi Y, Wilkerson MD, et al. Integrated Genomic Analysis Identifies Clinically Relevant Subtypes of Glioblastoma Characterized by Abnormalities in PDGFRA, IDH1, EGFR, and NF1. Cancer Cell (2010) 17(1):98-110. doi: 10.1016/j.ccr.2009.12.020

97. Luoto S, Hermelo I, Vuorinen EM, Hannus P, Kesseli J, Nykter M, et al. Computational Characterization of Suppressive Immune Microenvironments in Glioblastoma. Cancer Res (2018) 78(19):5574-85. doi: 10.1158/0008-5472.CAN-17-3714

98. Wang Q, Hu B, Hu X, Kim H, Squatrito M, Scarpace L, et al. Tumor Evolution of Glioma-Intrinsic Gene Expression Subtypes Associates With Immunological Changes in the Microenvironment. Cancer Cell (2017) 32 (1):42-56.e6. doi: 10.1016/j.ccell.2017.06.003

99. Rutledge WC, Kong J, Gao J, Gutman DA, Cooper LA, Appin C, et al. Tumor-Infiltrating Lymphocytes in Glioblastoma are Associated With Specific Genomic Alterations and Related to Transcriptional Class. Clin Cancer Res (2013) 19(18):4951-60. doi: 10.1158/1078-0432.CCR-13-0551

100. Kohanbash G, Carrera DA, Shrivastav S, Ahn BJ, Jahan N, Mazor T, et al. Isocitrate Dehydrogenase Mutations Suppress STAT1 and CD8+ T Cell Accumulation in Gliomas. J Clin Invest (2017) 127(4):1425-37. doi: 10.1172/ JCI90644

101. Berghoff AS, Kiesel B, Widhalm G, Wilhelm D, Rajky O, Kurscheid S, et al. Correlation of Immune Phenotype With IDH Mutation in Diffuse Glioma. Neuro-oncology (2017) 19(11):1460-8. doi: 10.1093/neuonc/nox054

102. Plant AS, Koyama S, Sinai C, Solomon IH, Griffin GK, Ligon KL, et al. Immunophenotyping of Pediatric Brain Tumors: Correlating Immune Infiltrate With Histology, Mutational Load, and Survival and Assessing Clonal T Cell Response. J Neuro-Oncol (2018) 137(2):269-78. doi: 10.1007/s11060-017-2737-9

103. Griesinger AM, Birks DK, Donson AM, Amani V, Hoffman LM, Waziri A, et al. Characterization of Distinct Immunophenotypes Across Pediatric Brain Tumor Types. J Immunol (2013) 191(9):4880-8. doi: 10.4049/jimmunol.1301966

104. Lieberman NA, DeGolier K, Kovar HM, Davis A, Hoglund V, Stevens J, et al. Characterization of the Immune Microenvironment of Diffuse Intrinsic Pontine Glioma: Implications for Development of Immunotherapy. Neurooncology (2019) 21(1):83-94. doi: 10.1093/neuonc/noy145

105. Fabiani MG, Haase S, Kadiyala P, Alghamri M, Comba A, Nuñez F, et al. Tmod-02. Characterization of the Tumor Immune Microenvironment in a Pediatric High Grade Glioma Mouse Model Harboring the H3. 3-G34r Mutation. Neuro-oncology (2019) 21(Supplement_2):ii121-ii. doi: 10.1093/ neuonc/noz036.241

106. Garcia-Fabiani MB, Kadiyala P, Haase S, Alghamri M, Comba A, Nunez F, et al. Pdtm-20. The Histone Mutation H3. 3-G34r Encountered in Pediatric
High Grade Glioma Modifies the Tumor Immune Microenvironment Rendering it More Permissive for Immune Mediated Therapies. Neurooncology (2019) 21(Supplement_6). doi: 10.1093/neuonc/noz175.796

107. Walter RB, Press OW, Pagel JM. Pretargeted Radioimmunotherapy for Hematologic and Other Malignancies. Cancer Biother Radiopharm (2010) 25(2):125-42. doi: 10.1089/cbr.2010.0759

108. Fukuya Y, Ikuta S, Maruyama T, Nitta M, Saito T, Tsuzuki S, et al. Tumor Recurrence Patterns After Surgical Resection of Intracranial Low-Grade Gliomas. J Neuro-Oncol (2019) 144(3):519-28. doi: 10.1007/s11060-01903250-8

109. Joo KM, Kim J, Jin J, Kim M, Seol HJ, Muradov J, et al. Patient-Specific Orthotopic Glioblastoma Xenograft Models Recapitulate the Histopathology and Biology of Human Glioblastomas in Situ. Cell Rep (2013) 3(1):260-73. doi: $10.1016 /$ j.celrep.2012.12.013

110. Harder BG, Blomquist MR, Wang J, Kim AJ, Woodworth GF, Winkles JA, et al. Developments in Blood-Brain Barrier Penetrance and Drug Repurposing for Improved Treatment of Glioblastoma. Front Oncol (2018) 8:462. doi: 10.3389/fonc.2018.00462

111. Weiss T, Puca E, Silginer M, Hemmerle T, Pazahr S, Bink A, et al. Immunocytokines are a Promising Immunotherapeutic Approach Against Glioblastoma. Sci Transl Med (2020) 12(564):eabb2311. doi: 10.1126/ scitranslmed.abb2311

112. DiGrande S. Is Immunotherapy the Future of Glioblastoma Treatment? Am J Managed Care (2019) 25(2):74-5.

113. da Hora CC, Schweiger MW, Wurdinger T, Tannous BA. Patient-Derived Glioma Models: From Patients to Dish to Animals. Cells (2019) 8(10):1177. doi: 10.3390/cells 8101177

114. Ogawa J, Pao GM, Shokhirev MN, Verma IM. Glioblastoma Model Using Human Cerebral Organoids. Cell Rep (2018) 23(4):1220-9. doi: 10.1016/ j.celrep.2018.03.105

115. Caretti V, Sewing AC, Lagerweij T, Schellen P, Bugiani M, Jansen MH, et al. Human Pontine Glioma Cells can Induce Murine Tumors. Acta Neuropathol (2014) 127(6):897-909. doi: 10.1007/s00401-014-1272-4

116. Qin H, Janowski M, Pearl MS, Malysz-Cymborska I, Li S, Eberhart CG, et al. Rabbit Model of Human Gliomas: Implications for Intra-Arterial Drug Delivery. PloS One (2017) 12(1):e0169656. doi: 10.1371/journal.pone. 0169656

117. Lan X, Kedziorek DA, Chu C, Jablonska A, Li S, Kai M, et al. Modeling Human Pediatric and Adult Gliomas in Immunocompetent Mice Through Costimulatory Blockade. Oncoimmunology (2020) 9(1):1776577. doi: 10.1080/2162402X.2020.1776577

118. Badie B, Bartley B, Schartner J. Differential Expression of MHC Class II and B7 Costimulatory Molecules by Microglia in Rodent Gliomas. J Neuroimmunol (2002) 133(1-2):39-45. doi: 10.1016/S0165-5728(02) 00350-8

119. Oh T, Fakurnejad S, Sayegh ET, Clark AJ, Ivan ME, Sun MZ, et al. Immunocompetent Murine Models for the Study of Glioblastoma Immunotherapy. J Transl Med (2014) 12:107. doi: 10.1186/1479-5876-12-107

120. Paul AK, Ciesielski MJ, Sajjad M, Wang X, Ferrone S, Abdel-Nabi H, et al. Expression of HMP/AN2, a Melanoma Associated Antigen, in Murine Cerebral Gliomas: Potential for Radioimmunotargeting. J Neurooncol (2009) 94(1):21-30. doi: 10.1007/s11060-009-9798-3

121. Chen ML, Pittet MJ, Gorelik L, Flavell RA, Weissleder R, von Boehmer H, et al. Regulatory T Cells Suppress Tumor-Specific CD8 T Cell Cytotoxicity Through TGF-Beta Signals In Vivo. Proc Natl Acad Sci USA (2005) 102 (2):419-24. doi: 10.1073/pnas.0408197102

122. Ueda R, Fujita M, Zhu X, Sasaki K, Kastenhuber ER, Kohanbash G, et al. Systemic Inhibition of Transforming Growth Factor-Beta in Glioma-Bearing Mice Improves the Therapeutic Efficacy of Glioma-Associated Antigen Peptide Vaccines. Clin Cancer Res (2009) 15(21):6551-9. doi: 10.1158/ 1078-0432.CCR-09-1067

123. Prins RM, Odesa SK, Liau LM. Immunotherapeutic Targeting of Shared Melanoma-Associated Antigens in a Murine Glioma Model. Cancer Res (2003) 63(23):8487-91.

124. Curtin JF, Candolfi M, Fakhouri TM, Liu C, Alden A, Edwards M, et al. Treg Depletion Inhibits Efficacy of Cancer Immunotherapy: Implications for Clinical Trials. PloS One (2008) 3(4):e1983. doi: 10.1371/journal.pone. 0001983 
125. Pilkington GJ, Darling JL, Lantos PL, Thomas DG. Cell Lines (Vmdk) Derived From a Spontaneous Murine Astrocytoma. Morphological and Immunocytochemical Characterization. J Neurol Sci (1983) 62(1-3):11539. doi: 10.1016/0022-510X(83)90193-4

126. Sampson JH, Ashley DM, Archer GE, Fuchs HE, Dranoff G, Hale LP, et al. Characterization of a Spontaneous Murine Astrocytoma and Abrogation of its Tumorigenicity by Cytokine Secretion. Neurosurgery (1997) 41(6):136572. discussion 72-3. doi: 10.1097/00006123-199712000-00024

127. Miller J, Eisele G, Tabatabai G, Aulwurm S, von Kurthy G, Stitz L, et al. Soluble CD70: A Novel Immunotherapeutic Agent for Experimental Glioblastoma. J Neurosurg (2010) 113(2):280-5. doi: 10.3171/2009.11.JNS09901

128. Sampson JH, Choi BD, Sanchez-Perez L, Suryadevara CM, Snyder DJ, Flores CT, et al. Egfrviii Mcar-Modified T-Cell Therapy Cures Mice With Established Intracerebral Glioma and Generates Host Immunity Against Tumor-Antigen Loss. Clin Cancer Res (2014) 20(4):972-84. doi: 10.1158/ 1078-0432.CCR-13-0709

129. Martinez-Murillo R, Martinez A. Standardization of an Orthotopic Mouse Brain Tumor Model Following Transplantation of CT-2A Astrocytoma Cells. Histol Histopathol (2007) 22(12):1309-26. doi: 10.14670/HH-22.1309

130. Binello E, Qadeer ZA, Kothari HP, Emdad L, Germano IM. Stemness of the CT-2A Immunocompetent Mouse Brain Tumor Model: Characterization In Vitro. J Cancer (2012) 3:166-74. doi: 10.7150/jca.4149

131. Shelton LM, Mukherjee P, Huysentruyt LC, Urits I, Rosenberg JA, Seyfried TN. A Novel Pre-Clinical In Vivo Mouse Model for Malignant Brain Tumor Growth and Invasion. J Neurooncol (2010) 99(2):165-76. doi: 10.1007/ s11060-010-0115-y

132. Lee J, Kotliarova S, Kotliarov Y, Li A, Su Q, Donin NM, et al. Tumor Stem Cells Derived From Glioblastomas Cultured in Bfgf and EGF More Closely Mirror the Phenotype and Genotype of Primary Tumors Than do SerumCultured Cell Lines. Cancer Cell (2006) 9(5):391-403. doi: 10.1016/ j.ccr.2006.03.030

133. Marsh J, Mukherjee P, Seyfried TN. Akt-Dependent Proapoptotic Effects of Dietary Restriction on Late-Stage Management of a Phosphatase and Tensin Homologue/Tuberous Sclerosis Complex 2-Deficient Mouse Astrocytoma. Clin Cancer Res (2008) 14(23):7751-62. doi: 10.1158/1078-0432.CCR-080213

134. Waldron JS, Yang I, Han S, Tihan T, Sughrue ME, Mills SA, et al. Implications for Immunotherapy of Tumor-Mediated T-Cell Apoptosis Associated With Loss of the Tumor Suppressor PTEN in Glioblastoma. J Clin Neurosci (2010) 17(12):1543-7. doi: 10.1016/j.jocn.2010.04.021

135. Weiner NE, Pyles RB, Chalk CL, Balko MG, Miller MA, Dyer CA, et al. A Syngeneic Mouse Glioma Model for Study of Glioblastoma Therapy. J Neuropathol Exp Neurol (1999) 58(1):54-60. doi: 10.1097/00005072199901000-00007

136. Dyer CA, Philibotte T. A Clone of the MOCH-1 Glial Tumor in Culture: Multiple Phenotypes Expressed Under Different Environmental Conditions. J Neuropathol Exp Neurol (1995) 54(6):852-63. doi: 10.1097/00005072199511000-00012

137. Higgins RJ, McKisic M, Dickinson PJ, Jimenez DF, Dow SW, Tripp LD, et al. Growth Inhibition of an Orthotopic Glioblastoma in Immunocompetent Mice by Cationic Lipid-DNA Complexes. Cancer Immunol Immunother (2004) 53(4):338-44. doi: 10.1007/s00262-003-0447-y

138. Markert JM, Cody JJ, Parker JN, Coleman JM, Price KH, Kern ER, et al. Preclinical Evaluation of a Genetically Engineered Herpes Simplex Virus Expressing Interleukin-12. J Virol (2012) 86(9):5304-13. doi: 10.1128/ JVI.06998-11

139. Becher OJ, Holland EC. Genetically Engineered Models Have Advantages Over Xenografts for Preclinical Studies. Cancer Res (2006) 66(7):3355-9. doi: 10.1158/0008-5472.CAN-05-3827

140. Ahronian LG, Lewis BC. Using the RCAS-TVA System to Model Human Cancer in Mice. Cold Spring Harbor Protoc (2014) 2014(11):pdb.top069831. doi: 10.1101/pdb.top069831

141. Hambardzumyan D, Amankulor NM, Helmy KY, Becher OJ, Holland EC. Modeling Adult Gliomas Using RCAS/T-Va Technology. Trans Oncol (2009) 2(2):89-IN6. doi: 10.1593/tlo.09100

142. Fomchenko EI, Holland EC. Mouse Models of Brain Tumors and Their Applications in Preclinical Trials. Clin Cancer Res (2006) 12(18):5288-97. doi: 10.1158/1078-0432.CCR-06-0438
143. Holland EC, Hively WP, DePinho RA, Varmus HE. A Constitutively Active Epidermal Growth Factor Receptor Cooperates With Disruption of G1 CellCycle Arrest Pathways to Induce Glioma-Like Lesions in Mice. Genes Dev (1998) 12(23):3675-85. doi: 10.1101/gad.12.23.3675

144. Kong L-Y, Wu AS, Doucette T, Wei J, Priebe W, Fuller GN, et al. Intratumoral Mediated Immunosuppression is Prognostic in Genetically Engineered Murine Models of Glioma and Correlates to Immunotherapeutic Responses. Clin Cancer Res (2010) 16(23):5722-33. doi: 10.1158/10780432.CCR-10-1693

145. Izsvak Z, Ivics Z. Sleeping Beauty Transposition: Biology and Applications for Molecular Therapy. Mol Ther (2004) 9(2):147-56. doi: 10.1016/ j.ymthe.2003.11.009

146. Kebriaei P, Izsvak Z, Narayanavari SA, Singh H, Ivics Z. Gene Therapy With the Sleeping Beauty Transposon System. Trends Genet (2017) 33(11):852-70. doi: $10.1016 /$ j.tig.2017.08.008

147. Calinescu AA, Núñez FJ, Koschmann C, Kolb BL, Lowenstein PR, Castro MG. Transposon Mediated Integration of Plasmid DNA Into the Subventricular Zone of Neonatal Mice to Generate Novel Models of Glioblastoma. J Vis Exp (2015) 96:52443. doi: 10.3791/52443

148. Koschmann C, Calinescu AA, Nunez FJ, Mackay A, Fazal-Salom J, Thomas D, et al. ATRX Loss Promotes Tumor Growth and Impairs Nonhomologous End Joining DNA Repair in Glioma. Sci Transl Med (2016) 8(328):328ra28. doi: $10.1126 /$ scitranslmed.aac8228

149. Koschmann C, Lowenstein PR, Castro MG. ATRX Mutations and Glioblastoma: Impaired DNA Damage Repair, Alternative Lengthening of Telomeres, and Genetic Instability. Mol Cell Oncol (2016) 3(3):e1167158. doi: 10.1080/23723556.2016.1167158

150. Garcia-Fabiani MB, Comba A, Kadiyala P, Haase S, Núñez FJ, Altshuler D, et al. Isolation and Characterization of Immune Cells From the Tumor Microenvironment of Genetically Engineered Pediatric High-Grade Glioma Models Using the Sleeping Beauty Transposon System. Methods Enzymol (2020) 632:369-88. doi: 10.1016/bs.mie.2019.05.023

151. Patel SK, Hartley RM, Wei X, Furnish R, Escobar-Riquelme F, Bear H, et al. Generation of Diffuse Intrinsic Pontine Glioma Mouse Models by Brainstem-Targeted In Utero Electroporation. Neuro-oncology (2020) 22 (3):381-92. doi: 10.1093/neuonc/noz197

152. Aslan K, Turco V, Blobner J, Sonner JK, Liuzzi AR, Núñez NG, et al. Heterogeneity of Response to Immune Checkpoint Blockade in Hypermutated Experimental Gliomas. Nat Commun (2020) 11(1):931. doi: 10.1038/s41467-020-14642-0

153. Zhao Y, Shuen TWH, Toh TB, Chan XY, Liu M, Tan SY, et al. Development of a New Patient-Derived Xenograft Humanised Mouse Model to Study Human-Specific Tumour Microenvironment and Immunotherapy. Gut (2018) 67(10):1845-54. doi: 10.1136/gutjnl-2017-315201

154. Mathews S, Branch Woods A, Katano I, Makarov E, Thomas MB, Gendelman HE, et al. Human Interleukin-34 Facilitates Microglia-Like Cell Differentiation and Persistent HIV-1 Infection in Humanized Mice. Mol Neurodegener (2019) 14(1):12. doi: 10.1186/s13024-019-0311-y

155. Klein E, Hau AC, Oudin A, Golebiewska A, Niclou SP. Glioblastoma Organoids: Pre-Clinical Applications and Challenges in the Context of Immunotherapy. Front Oncol (2020) 10:604121. doi: 10.3389/fonc.2020. 604121

156. Ashizawa T, Iizuka A, Nonomura C, Kondou R, Maeda C, Miyata H, et al. Antitumor Effect of Programmed Death-1 (PD-1) Blockade in Humanized the NOG-MHC Double Knockout Mouse. Clin Cancer Res (2017) 23(1):14958. doi: 10.1158/1078-0432.CCR-16-0122

157. Jacob F, Ming GL, Song H. Generation and Biobanking of Patient-Derived Glioblastoma Organoids and Their Application in CAR T Cell Testing. Nat Protoc (2020) 15(12):4000-33. doi: 10.1038/s41596-020-0402-9

158. Jacob F, Salinas RD, Zhang DY, Nguyen PTT, Schnoll JG, Wong SZH, et al. A Patient-Derived Glioblastoma Organoid Model and Biobank Recapitulates Inter- and Intra-Tumoral Heterogeneity. Cell (2020) 180(1):188-204.e22. doi: 10.1016/j.cell.2019.11.036

159. Richmond A, Su Y. Mouse Xenograft Models vs GEM Models for Human Cancer Therapeutics. Dis Model Mech (2008) 1(2-3):78-82. doi: 10.1242/ dmm.000976

160. Topalian SL. Targeting Immune Checkpoints in Cancer Therapy. JAMA (2017) 318(17):1647-8. doi: 10.1001/jama.2017.14155 
161. Brunet JF, Denizot F, Luciani MF, Roux-Dosseto M, Suzan M, Mattei MG, et al. A New Member of the Immunoglobulin Superfamily-CTLA-4. Nature (1987) 328(6127):267-70. doi: 10.1038/328267a0

162. Waldman AD, Fritz JM, Lenardo MJ. A Guide to Cancer Immunotherapy: From T Cell Basic Science to Clinical Practice. Nat Rev Immunol (2020) 20 (11):651-68. doi: 10.1038/s41577-020-0306-5

163. Leach DR, Krummel MF, Allison JP. Enhancement of Antitumor Immunity by CTLA-4 Blockade. Science (1996) 271(5256):1734-6. doi: 10.1126/ science.271.5256.1734

164. Hodi FS, Mihm MC, Soiffer RJ, Haluska FG, Butler M, Seiden MV, et al. Biologic Activity of Cytotoxic T Lymphocyte-Associated Antigen 4 Antibody Blockade in Previously Vaccinated Metastatic Melanoma and Ovarian Carcinoma Patients. Proc Natl Acad Sci USA (2003) 100(8):4712-7. doi: 10.1073/pnas.0830997100

165. Quezada SA, Peggs KS. Exploiting CTLA-4, PD-1 and PD-L1 to Reactivate the Host Immune Response Against Cancer. Br J Cancer (2013) 108(8):15605. doi: $10.1038 / b j c .2013 .117$

166. Calabro L, Morra A, Fonsatti E, Cutaia O, Amato G, Giannarelli D, et al. Tremelimumab for Patients With Chemotherapy-Resistant Advanced Malignant Mesothelioma: An Open-Label, Single-Arm, Phase 2 Trial. Lancet Oncol (2013) 14(11):1104-11. doi: 10.1016/S1470-2045(13)70381-4

167. Fecci PE, Ochiai H, Mitchell DA, Grossi PM, Sweeney AE, Archer GE, et al. Systemic CTLA-4 Blockade Ameliorates Glioma-Induced Changes to the CD4+ T Cell Compartment Without Affecting Regulatory T-Cell Function. Clin Cancer Res (2007) 13(7):2158-67. doi: 10.1158/1078-0432.CCR-062070

168. Reardon DA, Gokhale PC, Klein SR, Ligon KL, Rodig SJ, Ramkissoon SH, et al. Glioblastoma Eradication Following Immune Checkpoint Blockade in an Orthotopic, Immunocompetent Model. Cancer Immunol Res (2016) 4 (2):124-35. doi: 10.1158/2326-6066.CIR-15-0151

169. Wang Z, Zhang C, Liu X, Wang Z, Sun L, Li G, et al. Molecular and Clinical Characterization of PD-L1 Expression at Transcriptional Level Via 976 Samples of Brain Glioma. Oncoimmunology (2016) 5(11):e1196310. doi: 10.1080/2162402X.2016.1196310

170. Genoud V, Marinari E, Nikolaev SI, Castle JC, Bukur V, Dietrich PY, et al. Responsiveness to Anti-PD-1 and Anti-CTLA-4 Immune Checkpoint Blockade in SB28 and GL261 Mouse Glioma Models. Oncoimmunology (2018) 7(12):e1501137. doi: 10.1080/2162402X.2018.1501137

171. Sanders S, Debinski W. Challenges to Successful Implementation of the Immune Checkpoint Inhibitors for Treatment of Glioblastoma. Int J Mol Sci (2020) 21(8):2759. doi: 10.3390/ijms21082759

172. Omuro A, Vlahovic G, Lim M, Sahebjam S, Baehring J, Cloughesy T, et al. Nivolumab With or Without Ipilimumab in Patients With Recurrent Glioblastoma: Results From Exploratory Phase I Cohorts of Checkmate 143. Neuro Oncol (2018) 20(5):674-86. doi: 10.1093/neuonc/nox208

173. Ishida Y, Agata Y, Shibahara K, Honjo T. Induced Expression of PD-1, a Novel Member of the Immunoglobulin Gene Superfamily, Upon Programmed Cell Death. EMBO J (1992) 11(11):3887-95. doi: 10.1002/ j.1460-2075.1992.tb05481.x

174. Carreno BM, Collins M. The B7 Family of Ligands and its Receptors: New Pathways for Costimulation and Inhibition of Immune Responses. Annu Rev Immunol (2002) 20:29-53. doi: 10.1146/annurev.immunol.20.091101.091806

175. Fife BT, Bluestone JA. Control of Peripheral T-Cell Tolerance and Autoimmunity Via the CTLA-4 and PD-1 Pathways. Immunol Rev (2008) 224:166-82. doi: 10.1111/j.1600-065X.2008.00662.x

176. Liang SC, Latchman YE, Buhlmann JE, Tomczak MF, Horwitz BH, Freeman GJ, et al. Regulation of PD-1, PD-L1, and PD-L2 Expression During Normal and Autoimmune Responses. Eur J Immunol (2003) 33(10):2706-16. doi: 10.1002/eji.200324228

177. Sharpe AH, Freeman GJ. The B7-CD28 Superfamily. Nat Rev Immunol (2002) 2(2):116-26. doi: 10.1038/nri727

178. Xu S, Tang L, Li X, Fan F, Liu Z. Immunotherapy for Glioma: Current Management and Future Application. Cancer Lett (2020) 476:1-12. doi: 10.1016/j.canlet.2020.02.002

179. Marzec M, Zhang Q, Goradia A, Raghunath PN, Liu X, Paessler M, et al. Oncogenic Kinase NPM/ALK Induces Through STAT3 Expression of Immunosuppressive Protein CD274 (PD-L1, B7-H1). Proc Natl Acad Sci USA (2008) 105(52):20852-7. doi: 10.1073/pnas.0810958105
180. Green MR, Rodig S, Juszczynski P, Ouyang J, Sinha P, O’Donnell E, et al. Constitutive AP-1 Activity and EBV Infection Induce PD-L1 in Hodgkin Lymphomas and Posttransplant Lymphoproliferative Disorders: Implications for Targeted Therapy. Clin Cancer Res (2012) 18(6):1611-8. doi: 10.1158/1078-0432.CCR-11-1942

181. Jiang X, Zhou J, Giobbie-Hurder A, Wargo J, Hodi FS. The Activation of MAPK in Melanoma Cells Resistant to BRAF Inhibition Promotes PD-L1 Expression That is Reversible by MEK and PI3K Inhibition. Clin Cancer Res (2013) 19(3):598-609. doi: 10.1158/1078-0432.CCR-12-2731

182. Crane C, Panner A, Pieper RO, Arbiser J, Parsa AT. Honokiol-Mediated Inhibition of PI3K/Mtor Pathway: A Potential Strategy to Overcome Immunoresistance in Glioma, Breast, and Prostate Carcinoma Without Impacting T Cell Function. J Immunother (2009) 32(6):585-92. doi: 10.1097/CJI.0b013e3181a8efe6

183. Pardoll DM. The Blockade of Immune Checkpoints in Cancer Immunotherapy. Nat Rev Cancer (2012) 12(4):252-64. doi: 10.1038/nrc3239

184. Ribas A. Adaptive Immune Resistance: How Cancer Protects From Immune Attack. Cancer Discovery (2015) 5(9):915-9. doi: 10.1158/2159-8290.CD-150563

185. Arasanz H, Gato-Canas M, Zuazo M, Ibanez-Vea M, Breckpot K, Kochan G, et al. PD1 Signal Transduction Pathways in T Cells. Oncotarget (2017) 8 (31):51936-45. doi: 10.18632/oncotarget.17232

186. Grupp SA, Kalos M, Barrett D, Aplenc R, Porter DL, Rheingold SR, et al. Chimeric Antigen Receptor-Modified T Cells for Acute Lymphoid Leukemia. N Engl J Med (2013) 368(16):1509-18. doi: 10.1056/NEJMoa1215134

187. Larkin J, Chiarion-Sileni V, Gonzalez R, Grob JJ, Cowey CL, Lao CD, et al. Combined Nivolumab and Ipilimumab or Monotherapy in Untreated Melanoma. N Engl J Med (2015) 373(1):23-34. doi: 10.1056/ NEJMoa1504030

188. Brahmer J, Reckamp KL, Baas P, Crinò L, Eberhardt WE, Poddubskaya E, et al. Nivolumab Versus Docetaxel in Advanced Squamous-Cell non-SmallCell Lung Cancer. N Engl J Med (2015) 373(2):123-35. doi: 10.1056/ NEJMoa1504627

189. Motzer RJ, Escudier B, McDermott DF, George S, Hammers HJ, Srinivas S, et al. Nivolumab Versus Everolimus in Advanced Renal-Cell Carcinoma. N Engl J Med (2015) 373(19):1803-13. doi: 10.1056/NEJMoa1510665

190. Huang BY, Zhan YP, Zong WJ, Yu CJ, Li JF, Qu YM, et al. The PD-1/B7-H1 Pathway Modulates the Natural Killer Cells Versus Mouse Glioma Stem Cells. PloS One (2015) 10(8):e0134715. doi: 10.1371/journal.pone.0134715

191. Wainwright DA, Chang AL, Dey M, Balyasnikova IV, Kim CK, Tobias A, et al. Durable Therapeutic Efficacy Utilizing Combinatorial Blockade Against IDO, CTLA-4, and PD-L1 in Mice With Brain Tumors. Clin Cancer Res (2014) 20(20):5290-301. doi: 10.1158/1078-0432.CCR-14-0514

192. Zeng J, See AP, Phallen J, Jackson CM, Belcaid Z, Ruzevick J, et al. Anti-PD-1 Blockade and Stereotactic Radiation Produce Long-Term Survival in Mice With Intracranial Gliomas. Int J Radiat Oncol Biol Phys (2013) 86(2):343-9. doi: 10.1016/j.ijrobp.2012.12.025

193. Ott PA, Bang Y-J, Piha-Paul SA, Razak ARA, Bennouna J, Soria J-C, et al. TCell-Inflamed Gene-Expression Profile, Programmed Death Ligand 1 Expression, and Tumor Mutational Burden Predict Efficacy in Patients Treated With Pembrolizumab Across 20 Cancers: KEYNOTE-028. J Clin Oncol (2019) 37:(4):318-27. doi: 10.1200/JCO.2018.78.2276

194. Reardon DA, Omuro A, Brandes AA, Rieger J, Wick A, Sepulveda J, et al. OS10.3 Randomized Phase 3 Study Evaluating the Efficacy and Safety of Nivolumab vs Bevacizumab in Patients With Recurrent Glioblastoma: Checkmate 143. Neuro-Oncology (2017) 19(suppl_3):iii21-iii. doi: 10.1093/ neuonc/nox036.071

195. Lukas RV, Rodon J, Becker K, Wong ET, Shih K, Touat M, et al. Clinical Activity and Safety of Atezolizumab in Patients With Recurrent Glioblastoma. J Neurooncol (2018) 140(2):317-28. doi: 10.1007/s11060018-2955-9

196. Platten M, Wick W, Van den Eynde BJ. Tryptophan Catabolism in Cancer: Beyond IDO and Tryptophan Depletion. Cancer Res (2012) 72(21):5435-40. doi: 10.1158/0008-5472.CAN-12-0569

197. Prendergast GC, Smith C, Thomas S, Mandik-Nayak L, Laury-Kleintop L, Metz R, et al. Indoleamine 2,3-Dioxygenase Pathways of Pathogenic Inflammation and Immune Escape in Cancer. Cancer Immunol Immunother (2014) 63(7):721-35. doi: 10.1007/s00262-014-1549-4 
198. Toor SM, Sasidharan Nair V, Decock J, Elkord E. Immune Checkpoints in the Tumor Microenvironment. Semin Cancer Biol (2020) 65:1-12. doi: 10.1016/j.semcancer.2019.06.021

199. Uyttenhove C, Pilotte L, Théate I, Stroobant V, Colau D, Parmentier N, et al. Evidence for a Tumoral Immune Resistance Mechanism Based on Tryptophan Degradation by Indoleamine 2,3-Dioxygenase. Nat Med (2003) 9(10):1269-74. doi: 10.1038/nm934

200. Mitsuka K, Kawataki T, Satoh E, Asahara T, Horikoshi T, Kinouchi H. Expression of Indoleamine 2,3-Dioxygenase and Correlation With Pathological Malignancy in Gliomas. Neurosurgery (2013) 72(6):1031-9. doi: 10.1227/NEU.0b013e31828cf945

201. Hanihara M, Kawataki T, Oh-Oka K, Mitsuka K, Nakao A, Kinouchi H. Synergistic Antitumor Effect With Indoleamine 2,3-Dioxygenase Inhibition and Temozolomide in a Murine Glioma Model. J Neurosurg (2016) 124 (6):1594-601. doi: 10.3171/2015.5.JNS141901

202. Long GV, Dummer R, Hamid O, Gajewski TF, Caglevic C, Dalle S, et al. Epacadostat Plus Pembrolizumab Versus Placebo Plus Pembrolizumab in Patients With Unresectable or Metastatic Melanoma (ECHO-301/ KEYNOTE-252): A Phase 3, Randomised, Double-Blind Study. Lancet Oncol (2019) 20(8):1083-97. doi: 10.1016/S1470-2045(19)30274-8

203. Weenink B, French PJ, Sillevis Smitt PAE, Debets R, Geurts M. Immunotherapy in Glioblastoma: Current Shortcomings and Future Perspectives. Cancers (Basel) (2020) 12(3):751. doi: 10.3390/cancers 12030751

204. Cheong JE, Sun L. Targeting the IDO1/TDO2-KYN-Ahr Pathway for Cancer Immunotherapy - Challenges and Opportunities. Trends Pharmacol Sci (2018) 39(3):307-25. doi: 10.1016/j.tips.2017.11.007

205. Gutiérrez-Vázquez C, Quintana FJ. Regulation of the Immune Response by the Aryl Hydrocarbon Receptor. Immunity (2018) 48(1):19-33. doi: 10.1016/ j.immuni.2017.12.012

206. Kulasinghe A, Kapeleris J, Kenny L, Warkiani M, Vela I, Thiery J-P, et al. Abstract 1333: Isolation, Characterization and Expansion of Circulating Tumor Cells in Solid Cancers. Cancer Res (2019) 79(13 Supplement):1333-. doi: 10.1158/15387445.AM2019-1333

207. Perepechaeva ML, Grishanova AY. The Role of Aryl Hydrocarbon Receptor (Ahr) in Brain Tumors. Int J Mol Sci (2020) 21(8):2863. doi: 10.3390/ ijms 21082863

208. Graeber MB, Scheithauer BW, Kreutzberg GW. Microglia in Brain Tumors. Glia (2002) 40(2):252-9. doi: 10.1002/glia.10147

209. Thorsson V, Gibbs DL, Brown SD, Wolf D, Bortone DS, Ou Yang TH, et al. The Immune Landscape of Cancer. Immunity (2018) 48(4):812-30.e14. doi: 10.1016/j.immuni.2018.03.023

210. Hanisch UK, Kettenmann H. Microglia: Active Sensor and Versatile Effector Cells in the Normal and Pathologic Brain. Nat Neurosci (2007) 10(11):138794. doi: $10.1038 / \mathrm{nn} 1997$

211. Sielska M, Przanowski P, Wylot B, Gabrusiewicz K, Maleszewska M, Kijewska M, et al. Distinct Roles of CSF Family Cytokines in Macrophage Infiltration and Activation in Glioma Progression and Injury Response. J Pathol (2013) 230(3):310-21. doi: 10.1002/path.4192

212. Bettinger I, Thanos S, Paulus W. Microglia Promote Glioma Migration. Acta Neuropathol (2002) 103(4):351-5. doi: 10.1007/s00401-001-0472-x

213. Martins TA, Schmassmann P, Shekarian T, Boulay JL, Ritz MF, Zanganeh S, et al. Microglia-Centered Combinatorial Strategies Against Glioblastoma. Front Immunol (2020) 11:571951. doi: 10.3389/fimmu.2020.571951

214. Garris C, Pittet MJ. Therapeutically Reeducating Macrophages to Treat GBM. Nat Med (2013) 19(10):1207-8. doi: 10.1038/nm.3355

215. Pyonteck SM, Akkari L, Schuhmacher AJ, Bowman RL, Sevenich L, Quail DF, et al. CSF-1R Inhibition Alters Macrophage Polarization and Blocks Glioma Progression. Nat Med (2013) 19(10):1264-72. doi: 10.1038/nm.3337

216. Morisse MC, Jouannet S, Dominguez-Villar M, Sanson M, Idbaih A. Interactions Between Tumor-Associated Macrophages and Tumor Cells in Glioblastoma: Unraveling Promising Targeted Therapies. Expert Rev Neurother (2018) 18(9):729-37. doi: 10.1080/14737175.2018.1510321

217. Saha D, Martuza RL, Rabkin SD. Macrophage Polarization Contributes to Glioblastoma Eradication by Combination Immunovirotherapy and Immune Checkpoint Blockade. Cancer Cell (2017) 32(2):253-67.e5. doi: 10.1016/j.ccell.2017.07.006

218. Poli A, Wang J, Domingues O, Planagumà J, Yan T, Rygh CB, et al. Targeting Glioblastoma With NK Cells and Mab Against NG2/CSPG4 Prolongs
Animal Survival. Oncotarget (2013) 4(9):1527-46. doi: 10.18632/ oncotarget.1291

219. Kloepper J, Riedemann L, Amoozgar Z, Seano G, Susek K, Yu V, et al. Ang-2/ VEGF Bispecific Antibody Reprograms Macrophages and Resident Microglia to Anti-Tumor Phenotype and Prolongs Glioblastoma Survival. Proc Natl Acad Sci USA (2016) 113(16):4476-81. doi: 10.1073/ pnas. 1525360113

220. Peterson TE, Kirkpatrick ND, Huang Y, Farrar CT, Marijt KA, Kloepper J, et al. Dual Inhibition of Ang-2 and VEGF Receptors Normalizes Tumor Vasculature and Prolongs Survival in Glioblastoma by Altering Macrophages. Proc Natl Acad Sci USA (2016) 113(16):4470-5. doi: 10.1073/pnas.1525349113

221. Thomas RP, Nagpal S, Iv M, Soltys SG, Bertrand S, Pelpola JS, et al. Macrophage Exclusion After Radiation Therapy (MERT): A First in Human Phase I/II Trial Using a CXCR4 Inhibitor in Glioblastoma. Clin Cancer Res (2019) 25(23):6948-57. doi: 10.1158/1078-0432.CCR-19-1421

222. Ellert-Miklaszewska A, Wisniewski P, Kijewska M, Gajdanowicz P, Pszczolkowska D, Przanowski P, et al. Tumour-Processed Osteopontin and Lactadherin Drive the Protumorigenic Reprogramming of Microglia and Glioma Progression. Oncogene (2016) 35(50):6366-77. doi: 10.1038/ onc.2016.55

223. Willingham SB, Volkmer JP, Gentles AJ, Sahoo D, Dalerba P, Mitra SS, et al. The CD47-Signal Regulatory Protein Alpha (Sirpa) Interaction is a Therapeutic Target for Human Solid Tumors. Proc Natl Acad Sci USA (2012) 109(17):6662-7. doi: 10.1073/pnas.1121623109

224. Edris B, Weiskopf K, Volkmer AK, Volkmer JP, Willingham SB, ContrerasTrujillo $\mathrm{H}$, et al. Antibody Therapy Targeting the CD47 Protein is Effective in a Model of Aggressive Metastatic Leiomyosarcoma. Proc Natl Acad Sci USA (2012) 109(17):6656-61. doi: 10.1073/pnas.1121629109

225. Barclay AN, Van den Berg TK. The Interaction Between Signal Regulatory Protein Alpha (Sirpo) and CD47: Structure, Function, and Therapeutic Target. Annu Rev Immunol (2014) 32:25-50. doi: 10.1146/annurevimmunol-032713-120142

226. Hutter G, Theruvath J, Graef CM, Zhang M, Schoen MK, Manz EM, et al. Microglia are Effector Cells of CD47-Sirp $\alpha$ Antiphagocytic Axis Disruption Against Glioblastoma. Proc Natl Acad Sci USA (2019) 116(3):997-1006. doi: $10.1073 /$ pnas. 1721434116

227. Sikic BI, Lakhani N, Patnaik A, Shah SA, Chandana SR, Rasco D, et al. Firstin-Human, First-in-Class Phase I Trial of the Anti-CD47 Antibody Hu5F9G4 in Patients With Advanced Cancers. J Clin Oncol (2019) 37(12):946-53. doi: $10.1200 / J C O .18 .02018$

228. Dall'Olio F, Malagolini N, Trinchera M, Chiricolo M. Sialosignaling: Sialyltransferases as Engines of Self-Fueling Loops in Cancer Progression. Biochim Biophys Acta (2014) 1840(9):2752-64. doi: 10.1016/j.bbagen.2014.06.006

229. Li GZ, Zhang KN, Wang Z, Hu HM, Wang ZL, Huang RY, et al. Siglecs, Novel Immunotherapy Targets, Potentially Enhance the Effectiveness of Existing Immune Checkpoint Inhibitors in Glioma Immunotherapy. Onco Targets Ther (2019) 12:10263-73. doi: 10.2147/OTT.S223406

230. Wang J, Sun J, Liu LN, Flies DB, Nie X, Toki M, et al. Siglec-15 as an Immune Suppressor and Potential Target for Normalization Cancer Immunotherapy. Nat Med (2019) 25(4):656-66. doi: 10.1038/s41591-019-0374-x

231. Lang FF, Conrad C, Gomez-Manzano C, Yung WKA, Sawaya R, Weinberg JS, et al. Phase I Study of DNX-2401 (Delta-24-RGD) Oncolytic Adenovirus: Replication and Immunotherapeutic Effects in Recurrent Malignant Glioma. J Clin Oncol (2018) 36(14):1419-27. doi: 10.1200/JCO.2017.75.8219

232. Jiang H, Clise-Dwyer K, Ruisaard KE, Fan X, Tian W, Gumin J, et al. Delta24-RGD Oncolytic Adenovirus Elicits Anti-Glioma Immunity in an Immunocompetent Mouse Model. PloS One (2014) 9(5):e97407. doi: 10.1371/journal.pone.0097407

233. van den Bossche WBL, Kleijn A, Teunissen CE, Voerman JSA, Teodosio C, Noske DP, et al. Oncolytic Virotherapy in Glioblastoma Patients Induces a Tumor Macrophage Phenotypic Shift Leading to an Altered Glioblastoma Microenvironment. Neuro Oncol (2018) 20(11):1494-504. doi: 10.1093/ neuonc/noy082

234. Mahasa KJ, de Pillis L, Ouifki R, Eladdadi A, Maini P, Yoon AR, et al. Mesenchymal Stem Cells Used as Carrier Cells of Oncolytic Adenovirus Results in Enhanced Oncolytic Virotherapy. Sci Rep (2020) 10(1):425. doi: 10.1038/s41598-019-57240-x 
235. Jiang H, Rivera-Molina Y, Gomez-Manzano C, Clise-Dwyer K, Bover L, Vence LM, et al. Oncolytic Adenovirus and Tumor-Targeting Immune Modulatory Therapy Improve Autologous Cancer Vaccination. Cancer Res (2017) 77(14):3894. doi: 10.1158/0008-5472.CAN-17-0468

236. Zadeh G, Lang F, Daras M, Cloughesy T, Colman H, Ong S, et al. Atim-24. Interim Results of a Phase Ii Multicenter Study of the Conditionally Replicative Oncolytic Adenovirus Dnx-2401 With Pembrolizumab (Keytruda) for Recurrent Glioblastoma; Captive Study (Keynote-192). Neuro Oncol (2018) 20(Suppl 6):vi6-vi. doi: 10.1093/neuonc/noy148.019

237. Saha D, Martuza RL, Rabkin SD. Oncolytic Herpes Simplex Virus Immunovirotherapy in Combination With Immune Checkpoint Blockade to Treat Glioblastoma. Immunotherapy (2018) 10(9):779-86. doi: 10.2217/ imt-2018-0009

238. Todo T, Martuza RL, Rabkin SD, Johnson PA. Oncolytic Herpes Simplex Virus Vector With Enhanced MHC Class I Presentation and Tumor Cell Killing. Proc Natl Acad Sci U S A (2001) 98(11):6396-401. doi: 10.1073/ pnas. 101136398

239. Cheema TA, Wakimoto H, Fecci PE, Ning J, Kuroda T, Jeyaretna DS, et al. Multifaceted Oncolytic Virus Therapy for Glioblastoma in an Immunocompetent Cancer Stem Cell Model. Proc Natl Acad Sci USA (2013) 110(29):12006-11. doi: 10.1073/pnas.1307935110

240. Cheema TA, Fecci PE, Ning J, Rabkin SD. Immunovirotherapy for the Treatment of Glioblastoma. Oncoimmunology (2014) 3(1):e27218. doi: 10.4161/onci.27218

241. Todo T. Atim-14. Results of Phase Ii Clinical Trial of Oncolytic Herpes Virus G47D in Patients With Glioblastoma. Neuro Oncol (2019) 21 (Supplement_6):vi4-vi. doi: 10.1093/neuonc/noz175.014

242. Freeman AI, Zakay-Rones Z, Gomori JM, Linetsky E, Rasooly L, Greenbaum E, et al. Phase I/II Trial of Intravenous NDV-HUJ Oncolytic Virus in Recurrent Glioblastoma Multiforme. Mol Ther (2006) 13(1):221-8. doi: 10.1016/j.ymthe.2005.08.016

243. Angelova AL, Barf M, Geletneky K, Unterberg A, Rommelaere J. Immunotherapeutic Potential of Oncolytic H-1 Parvovirus: Hints of Glioblastoma Microenvironment Conversion Towards Immunogenicity. Viruses (2017) 9(12):382. doi: 10.3390/v9120382

244. Geletneky K, Kiprianova I, Ayache A, Koch R, Herrero YCM, Deleu L, et al. Regression of Advanced Rat and Human Gliomas by Local or Systemic Treatment With Oncolytic Parvovirus H-1 in Rat Models. Neuro Oncol (2010) 12(8):804-14. doi: 10.1093/neuonc/noq023

245. Grekova SP, Raykov Z, Zawatzky R, Rommelaere J, Koch U. Activation of a Glioma-Specific Immune Response by Oncolytic Parvovirus Minute Virus of Mice Infection. Cancer Gene Ther (2012) 19(7):468-75. doi: 10.1038/cgt.2012.20

246. Lim M, Xia Y, Bettegowda C, Weller M. Current State of Immunotherapy for Glioblastoma. Nat Rev Clin Oncol (2018) 15(7):422-42. doi: 10.1038/s41571018-0003-5

247. Hossain JA, Marchini A, Fehse B, Bjerkvig R, Miletic H. Suicide Gene Therapy for the Treatment of High-Grade Glioma: Past Lessons, Present Trends, and Future Prospects. Neuro-Oncol Adv (2020) 2(1):vdaa013. doi: 10.1093/noajnl/vdaa013

248. Bais SS, Chheda MG. A Fyn Romance: Tumor Cell Fyn Kinase Suppresses the Immune Microenvironment. Neuro-Oncology (2020) 22(6):746-7. doi: 10.1093/neuonc/noaa082

249. Young JS, Dayani F, Morshed RA, Okada H, Aghi MK. Immunotherapy for High Grade Gliomas: A Clinical Update and Practical Considerations for Neurosurgeons. World Neurosurg (2019) S1878-8750(19):30106-8. doi: 10.1016/j.wneu.2018.12.222

250. Park JH, Riviere I, Wang X, Bernal Y, Purdon T, Halton E, et al. Efficacy and Safety of CD19-Targeted 19-28z CAR Modified T Cells in Adult Patients With Relapsed or Refractory B-ALL. J Clin Oncol (2015) 33(15_suppl):7010. doi: $10.1200 /$ jco.2015.33.15_suppl.7010

251. Sommermeyer D, Hudecek M, Kosasih PL, Gogishvili T, Maloney DG, Turtle CJ, et al. Chimeric Antigen Receptor-Modified T Cells Derived From Defined CD8+ and CD4+ Subsets Confer Superior Antitumor Reactivity In Vivo. Leukemia (2016) 30(2):492-500. doi: 10.1038/leu.2015.247

252. Haase S, Nuñez FM, Gauss JC, Thompson S, Brumley E, Lowenstein P, et al. Hemispherical Pediatric High-Grade Glioma: Molecular Basis and Therapeutic Opportunities. Int J Mol Sci (2020) 21(24):9654. doi: 10.3390/ ijms 21249654
253. Samstein RM, Lee C-H, Shoushtari AN, Hellmann MD, Shen R, Janjigian YY, et al. Tumor Mutational Load Predicts Survival After Immunotherapy Across Multiple Cancer Types. Nat Genet (2019) 51(2):202-6. doi: 10.1038/ s41588-018-0312-8

254. Wang SS, Bandopadhayay P, Jenkins MR. Towards Immunotherapy for Pediatric Brain Tumors. Trends Immunol (2019) 40(8):748-61. doi: 10.1016/ j.it.2019.05.009

255. Sherman WJ, Vitaz TW. Nivolumab With Radiation Therapy in a Glioblastoma Patient With Lynch Syndrome. BMJ Case Rep (2021) 14(4): e241026. doi: 10.1136/bcr-2020-241026

256. D’Angelo F, Ceccarelli M, Tala, Garofano L, Zhang J, Frattini V, et al. The Molecular Landscape of Glioma in Patients With Neurofibromatosis 1. Nat Med (2019) 25(1):176-87. doi: 10.1038/s41591-018-0263-8

257. Brown CE, Alizadeh D, Starr R, Weng L, Wagner JR, Naranjo A, et al. Regression of Glioblastoma After Chimeric Antigen Receptor T-Cell Therapy. NEngl J Med (2016) 375(26):2561-9. doi: 10.1056/NEJMoa1610497

258. Mount CW, Majzner RG, Sundaresh S, Arnold EP, Kadapakkam M, Haile S, et al. Potent Antitumor Efficacy of Anti-GD2 CAR T Cells in H3-K27M(+) Diffuse Midline Gliomas. Nat Med (2018) 24(5):572-9. doi: 10.1038/s41591018-0006-x

259. Haase S, Belén Garcia-Fabiani M, Nunez F, Kadiyala P, Nunez F, Lowenstein P, et al. Pdtm-20. Elucidating Molecular Pathogenic Mechanisms of the Histone H3.3 G34r Mutation in Pediatric High-Grade Gliomas (Hggs). Neuro Oncol (2018) 20(Suppl 6):vi208. doi: 10.1093/neuonc/noy148.862

260. Vitanza NA, Biery MC, Myers C, Ferguson E, Zheng Y, Girard EJ, et al. Optimal Therapeutic Targeting by HDAC Inhibition in Biopsy-Derived Treatment-Naïve Diffuse Midline Glioma Models. Neuro Oncol (2021) 23 (3):376-86. doi: 10.1093/neuonc/noaa249

261. Herting CJ, Chen Z, Pitter KL, Szulzewsky F, Kaffes I, Kaluzova M, et al. Genetic Driver Mutations Define the Expression Signature and Microenvironmental Composition of High-Grade Gliomas. Glia (2017) 65 (12):1914-26. doi: 10.1002/glia.23203

262. Gabrilovich DI. Myeloid-Derived Suppressor Cells. Cancer Immunol Res (2017) 5(1):3-8. doi: 10.1158/2326-6066.CIR-16-0297

263. Elias D, Ditzel HJ. Fyn is an Important Molecule in Cancer Pathogenesis and Drug Resistance. Pharmacol Res (2015) 100:250-4. doi: 10.1016/j.phrs. 2015.08.010

264. Lee GH, Yoo KC, An Y, Lee HJ, Lee M, Uddin N, et al. FYN Promotes Mesenchymal Phenotypes of Basal Type Breast Cancer Cells Through STAT5/NOTCH2 Signaling Node. Oncogene (2018) 37(14):1857-68. doi: 10.1038/s41388-017-0114-y

265. Schenone S, Brullo C, Musumeci F, Biava M, Falchi F, Botta M. Fyn Kinase in Brain Diseases and Cancer: The Search for Inhibitors. Curr Med Chem (2011) 18(19):2921-42. doi: 10.2174/092986711796150531

266. Palacios EH, Weiss A. Function of the Src-Family Kinases, Lck and Fyn, in T-Cell Development and Activation. Oncogene (2004) 23(48):7990-8000. doi: 10.1038/sj.onc.1208074

267. Sugie K, Jeon MS, Grey HM. Activation of Naive CD4 T Cells by Anti-CD3 Reveals an Important Role for Fyn in Lck-Mediated Signaling. Proc Natl Acad Sci USA (2004) 101(41):14859-64. doi: 10.1073/pnas.0406168101

268. Yamauchi J, Miyamoto Y, Torii T, Takashima S, Kondo K, Kawahara K, et al. Phosphorylation of Cytohesin-1 by Fyn is Required for Initiation of Myelination and the Extent of Myelination During Development. Sci Signaling (2012) 5(243):ra69. doi: 10.1126/scisignal.2002802

269. Matrone C, Petrillo F, Nasso R, Ferretti G. Fyn Tyrosine Kinase as Harmonizing Factor in Neuronal Functions and Dysfunctions. Int $J$ Mol Sci (2020) 21(12):4444. doi: 10.3390/ijms21124444

270. Lu KV, Zhu S, Cvrljevic A, Huang TT, Sarkaria S, Ahkavan D, et al. Fyn and SRC are Effectors of Oncogenic Epidermal Growth Factor Receptor Signaling in Glioblastoma Patients. Cancer Res (2009) 69(17):6889-98. doi: 10.1158/ 0008-5472.CAN-09-0347

271. Yadav V, Denning MF. Fyn is Induced by Ras/PI3K/Akt Signaling and is Required for Enhanced Invasion/Migration. Mol Carcinog (2011) 50(5):34652. doi: 10.1002/mc.20716

272. Jensen AR, David SY, Liao C, Dai J, Keller ET, Al-Ahmadie H, et al. Fyn is Downstream of the HGF/MET Signaling Axis and Affects Cellular Shape and Tropism in PC3 Cells. Clin Cancer Res (2011) 17(10):3112-22. doi: 10.1158/ 1078-0432.CCR-10-1264 
273. Guo S, Ran H, Xiao D, Huang H, Mi L, Wang X, et al. NT5DC2 Promotes Tumorigenicity of Glioma Stem-Like Cells by Upregulating Fyn. Cancer Lett (2019) 454:98-107. doi: 10.1016/j.canlet.2019.04.003

274. Han X, Zhang W, Yang X, Wheeler CG, Langford CP, Wu L, et al. The Role of Src Family Kinases in Growth and Migration of Glioma Stem Cells. Int J Oncol (2014) 45(1):302-10. doi: 10.3892/ijo.2014.2432

275. Lewis-Tuffin LJ, Feathers R, Hari P, Durand N, Li Z, Rodriguez FJ, et al. Src Family Kinases Differentially Influence Glioma Growth and Motility. Mol Oncol (2015) 9(9):1783-98. doi: 10.1016/j.molonc.2015.06.001

276. Masserini M. Nanoparticles for Brain Drug Delivery. ISRN Biochem (2013) 2013. doi: $10.1155 / 2013 / 238428$

277. Gregory JV, Kadiyala P, Doherty R, Cadena M, Habeel S, Ruoslahti E, et al. Systemic Brain Tumor Delivery of Synthetic Protein Nanoparticles for Glioblastoma Therapy. Nat Commun (2020) 11(1):5687. doi: 10.1038/ s41467-020-19225-7

278. Ivashkiv LB. Ifngamma: Signalling, Epigenetics and Roles in Immunity, Metabolism, Disease and Cancer Immunotherapy. Nat Rev Immunol (2018) 18(9):545-58. doi: 10.1038/s41577-018-0029-Z

279. Mi Y, Hagan CTIV, Vincent BG, Wang AZ. Emerging Nano-/ Microapproaches for Cancer Immunotherapy. Adv Sci (2019) 6 (6):1801847. doi: 10.1002/advs.201801847

280. Kuai R, Ochyl LJ, Bahjat KS, Schwendeman A, Moon JJ. Designer Vaccine Nanodiscs for Personalized Cancer Immunotherapy. Nat Mater (2017) 16 (4):489-96. doi: 10.1038/nmat4822

281. Kuai R, Li D, Chen YE, Moon JJ, Schwendeman A. High-Density Lipoproteins: Nature's Multifunctional Nanoparticles. ACS Nano (2016) 10(3):3015-41. doi: 10.1021/acsnano.5b07522

282. Vanan MI, Underhill DA, Eisenstat DD. Targeting Epigenetic Pathways in the Treatment of Pediatric Diffuse (High Grade) Gliomas. Neurotherapeutics (2017) 14(2):274-83. doi: 10.1007/s13311-017-0514-2

283. Alexandrov LB, Nik-Zainal S, Wedge DC, Aparicio SAJR, Behjati S, Biankin $\mathrm{AV}$, et al. Signatures of Mutational Processes in Human Cancer. Nature (2013) 500:415. doi: 10.1038/nature12477

284. Ilyas S, Yang JC. Landscape of Tumor Antigens in T Cell Immunotherapy. J Immunol (Baltimore Md: 1950) (2015) 195(11):5117-22. doi: 10.4049/ jimmunol.1501657

285. Gusyatiner O, Hegi ME. Glioma Epigenetics: From Subclassification to Novel Treatment Options. Semin Cancer Biol (2018) 51:50-8. doi: 10.1016/ j.semcancer.2017.11.010

286. Cheng T, Xu Y. Effects of Enhancer of Zeste Homolog 2 (EZH2) Expression on Brain Glioma Cell Proliferation and Tumorigenesis. Med Sci Monit (2018) 24:7249-55. doi: 10.12659/MSM.909814

287. Orzan F, Pellegatta S, Poliani PL, Pisati F, Caldera V, Menghi F, et al. Enhancer of Zeste 2 (EZH2) is Up-Regulated in Malignant Gliomas and in Glioma Stem-Like Cells. Neuropathol Appl Neurobiol (2011) 37(4):381-94. doi: 10.1111/j.1365-2990.2010.01132.x

288. Olar A, Aldape KD. Using the Molecular Classification of Glioblastoma to Inform Personalized Treatment. J Pathol (2014) 232(2):165-77. doi: 10.1002/ path. 4282

289. Turcan S, Rohle D, Goenka A, Walsh LA, Fang F, Yilmaz E, et al. IDH1 Mutation is Sufficient to Establish the Glioma Hypermethylator Phenotype. Nature (2012) 483(7390):479-83. doi: 10.1038/nature10866

290. Federici L, Capelle L, Annereau M, Bielle F, Willekens C, Dehais C, et al. 5Azacitidine in Patients With IDH1/2-Mutant Recurrent Glioma. NeuroOncology (2020) 22(8):1226-8. doi: 10.1093/neuonc/noaa074

291. DiNardo C, de Botton S, Pollyea DA, Stein EM, Fathi AT, Roboz GJ, et al. Molecular Profiling and Relationship With Clinical Response in Patients With IDH1 Mutation-Positive Hematologic Malignancies Receiving AG120, a First-in-Class Potent Inhibitor of Mutant IDH1, in Addition to Data From the Completed Dose Escalation Portion of the Phase 1 Study. Blood (2015) 126(23):1306-. doi: 10.1182/blood.V126.23.1306.1306

292. Golub D, Iyengar N, Dogra S, Wong T, Bready D, Tang K, et al. Mutant Isocitrate Dehydrogenase Inhibitors as Targeted Cancer Therapeutics. Front Oncol (2019) 9:417-. doi: 10.3389/fonc.2019.00417

293. Popovici-Muller J, Lemieux RM, Artin E, Saunders JO, Salituro FG, Travins J, et al. Discovery of AG-120 (Ivosidenib): A First-in-Class Mutant IDH1 Inhibitor for the Treatment of IDH1 Mutant Cancers. ACS Med Chem Lett (2018) 9(4):300-5. doi: 10.1021/acsmedchemlett.7b00421
294. Borodovsky A, Salmasi V, Turcan S, Fabius AW, Baia GS, Eberhart CG, et al. 5-Azacytidine Reduces Methylation, Promotes Differentiation and Induces Tumor Regression in a Patient-Derived IDH1 Mutant Glioma Xenograft. Oncotarget (2013) 4(10):1737-47. doi: 10.18632/oncotarget.1408

295. Turcan S, Fabius AW, Borodovsky A, Pedraza A, Brennan C, Huse J, et al. Efficient Induction of Differentiation and Growth Inhibition in IDH1 Mutant Glioma Cells by the DNMT Inhibitor Decitabine. Oncotarget (2013) 4(10):1729-36. doi: 10.18632/oncotarget.1412

296. Mackenzie KJ, Carroll P, Martin C-A, Murina O, Fluteau A, Simpson DJ, et al. Cgas Surveillance of Micronuclei Links Genome Instability to Innate Immunity. Nature (2017) 548(7668):461-5. doi: 10.1038/nature23449

297. Cao J, Yan Q. Cancer Epigenetics, Tumor Immunity, and Immunotherapy. Trends Cancer (2020) 6(7):580-92. doi: 10.1016/j.trecan.2020.02.003

298. Chiou G-Y, Chien C-S, Wang M-L, Chen M-T, Yang Y-P, Yu Y-L, et al. Epigenetic Regulation of the Mir142-3p/Interleukin-6 Circuit in Glioblastoma. Mol Cell (2013) 52(5):693-706. doi: 10.1016/j.molcel.2013.11.009

299. West AC, Johnstone RW. New and Emerging HDAC Inhibitors for Cancer Treatment. J Clin Invest (2014) 124(1):30-9. doi: 10.1172/JCI69738

300. Camphausen K, Cerna D, Scott T, Sproull M, Burgan WE, Cerra MA, et al. Enhancement of In Vitro and In Vivo Tumor Cell Radiosensitivity by Valproic Acid. Int J Cancer (2005) 114(3):380-6. doi: 10.1002/ijc.20774

301. Was H, Krol SK, Rotili D, Mai A, Wojtas B, Kaminska B, et al. Histone Deacetylase Inhibitors Exert Anti-Tumor Effects on Human Adherent and Stem-Like Glioma Cells. Clin Epigenet (2019) 11(1):11. doi: 10.1186/s13148018-0598-5

302. Bolden JE, Peart MJ, Johnstone RW. Anticancer Activities of Histone Deacetylase Inhibitors. Nat Rev Drug Discovery (2006) 5(9):769-84. doi: $10.1038 / \mathrm{nrd} 2133$

303. Chinnaiyan P, Chowdhary S, Potthast L, Prabhu A, Tsai Y-Y, Sarcar B, et al. Phase I Trial of Vorinostat Combined With Bevacizumab and CPT-11 in Recurrent Glioblastoma. Neuro-oncology (2012) 14(1):93-100. doi: 10.1093/ neuonc/nor187

304. Friday BB, Anderson SK, Buckner J, Yu C, Giannini C, Geoffroy F, et al. Phase II Trial of Vorinostat in Combination With Bortezomib in Recurrent Glioblastoma: A North Central Cancer Treatment Group Study. NeuroOncology (2012) 14(2):215-21. doi: 10.1093/neuonc/nor198

305. Krauze AV, Myrehaug SD, Chang MG, Holdford DJ, Smith S, Shih J, et al. A Phase 2 Study of Concurrent Radiation Therapy, Temozolomide, and the Histone Deacetylase Inhibitor Valproic Acid for Patients With Glioblastoma. Int J Radiat Oncol Biol Phys (2015) 92(5):986-92. doi: 10.1016/j.ijrobp.2015.04.038

306. Lee DH, Ryu HW, Won HR, Kwon SH. Advances in Epigenetic Glioblastoma Therapy. Oncotarget (2017) 8(11):18577-89. doi: 10.18632/ oncotarget.14612

307. Pastori C, Daniel M, Penas C, Volmar CH, Johnstone AL, Brothers SP, et al. BET Bromodomain Proteins are Required for Glioblastoma Cell Proliferation. Epigenetics (2014) 9(4):611-20. doi: 10.4161/epi.27906

308. Cheng Z, Gong Y, Ma Y, Lu K, Lu X, Pierce LA, et al. Inhibition of BET Bromodomain Targets Genetically Diverse Glioblastoma. Clin Cancer Res (2013) 19(7):1748-59. doi: 10.1158/1078-0432.CCR-12-3066

309. Agrawal K, Das V, Vyas P, Hajdúch M. Nucleosidic DNA Demethylating Epigenetic Drugs - a Comprehensive Review From Discovery to Clinic. Pharmacol Ther (2018) 188:45-79. doi: 10.1016/j.pharmthera.2018.02.006

310. McClure JJ, Li X, Chou CJ. Advances and Challenges of HDAC Inhibitors in Cancer Therapeutics. Adv Cancer Res (2018) 138:183-211. doi: 10.1016/ bs.acr.2018.02.006

311. First EZH2 Inhibitor Approved-for Rare Sarcoma. Cancer Discov (2020) 10 (3):333. doi: 10.1158/2159-8290.CD-NB2020-006

312. Iorgulescu JB, Torre M, Harary M, Smith TR, Aizer AA, Reardon DA, et al. The Misclassification of Diffuse Gliomas: Rates and Outcomes. Clin Cancer Res (2019) 25(8):2656-63. doi: 10.1158/1078-0432.CCR-18-3101

313. Robinson C, Kleinschmidt-DeMasters B. IDH1-Mutation in Diffuse Gliomas in Persons Age 55 Years and Over. J Neuropathol Exp Neurol (2017) 76 (2):151-4. doi: 10.1093/jnen/nlw112

314. Lai A, Kharbanda S, Pope WB, Tran A, Solis OE, Peale F, et al. Evidence for Sequenced Molecular Evolution of IDH1 Mutant Glioblastoma From a Distinct Cell of Origin. J Clin Oncol (2011) 29(34):4482. doi: 10.1200/JCO.2010.33.8715

315. Lass U, Nümann A, von Eckardstein K, Kiwit J, Stockhammer F, HoraczekJA, et al. Clonal Analysis in Recurrent Astrocytic, Oligoastrocytic and Oligodendroglial 
Tumors Implicates IDH1-Mutation as Common Tumor Initiating Event. PloS One (2012) 7(7):e41298. doi: 10.1371/journal.pone.0041298

316. Lu C, Ward PS, Kapoor GS, Rohle D, Turcan S, Abdel-Wahab O, et al. IDH Mutation Impairs Histone Demethylation and Results in a Block to Cell Differentiation. Nature (2012) 483(7390):474-8. doi: 10.1038/nature10860

317. Urban DJ, Martinez NJ, Davis MI, Brimacombe KR, Cheff DM, Lee TD, et al. Assessing Inhibitors of Mutant Isocitrate Dehydrogenase Using a Suite of Pre-Clinical Discovery Assays. Sci Rep (2017) 7(1):1-15. doi: 10.1038/ s41598-017-12630-x

318. Bunse L, Pusch S, Bunse T, Sahm F, Sanghvi K, Friedrich M, et al. Suppression of Antitumor T Cell Immunity by the Oncometabolite (R)-2-Hydroxyglutarate. Nat Med (2018) 24(8):1192-203. doi: 10.1038/s41591-018-0095-6

319. Maxwell R, Jackson CM, Lim M. Clinical Trials Investigating Immune Checkpoint Blockade in Glioblastoma. Curr Treat Options Oncol (2017) 18 (8):51. doi: 10.1007/s11864-017-0492-y

320. Yeo AT, Charest A. Immune Checkpoint Blockade Biology in Mouse Models of Glioblastoma. J Cell Biochem (2017) 118(9):2516-27. doi: 10.1002/jcb.25948
321. Paugh BS, Qu C, Jones C, Liu Z, Adamowicz-Brice M, Zhang J, et al. Integrated Molecular Genetic Profiling of Pediatric High-Grade Gliomas Reveals Key Differences With the Adult Disease. J Clin Oncol (2010) 28 (18):3061-8. doi: 10.1200/JCO.2009.26.7252

Conflict of Interest: The authors declare that the research was conducted in the absence of any commercial or financial relationships that could be construed as a potential conflict of interest.

Copyright (c) 2021 Garcia-Fabiani, Haase, Comba, Carney, McClellan, Banerjee, Alghamri, Syed, Kadiyala, Nunez, Candolfi, Asad, Gonzalez, Aikins, Schwendeman, Moon, Lowenstein and Castro. This is an open-access article distributed under the terms of the Creative Commons Attribution License (CC BY). The use, distribution or reproduction in other forums is permitted, provided the original author(s) and the copyright owner(s) are credited and that the original publication in this journal is cited, in accordance with accepted academic practice. No use, distribution or reproduction is permitted which does not comply with these terms. 